\title{
Solvent Isotope Effects in Reactions of Human Medium-Chain Acyl-CoA Dehydrogenase Active Site Mutants ${ }^{\dagger}$
}

\author{
Robert Gradinaru, ${ }^{\S}$ Richard Schowen, ${ }^{\ddagger}$ and Sandro Ghisla*,§ \\ Department of Biology, University of Konstanz, D-78457 Konstanz, Germany, and \\ Simons Laboratories, Higuchi Biosciences Center, University of Kansas, 2095 Constant Avenue, Lawrence, Kansas 66047
}

\begin{abstract}
Glu376, the base involved in substrate $\alpha \mathrm{H}^{+}$abstraction at the active center of medium-chain acyl-CoA dehydrogenase (MCAD), has been mutated to Gln and Gly. The mutants are active; however, their rates of dehydrogenation are lowered by approximately 5 orders of magnitude. Binding of the substrate octanoyl-CoA to Glu376Gln-MCAD involves (at least) two steps. The ensuing dehydrogenation reaction that corresponds to reduction of the flavin cofactor also occurs in two phases. These are interpreted to consist of a first, reversible step, followed by a slower, practically irreversible one. For Glu376Gln$\mathrm{MCAD}$, the $\log$ of the rates of dehydrogenation increases linearly with $\mathrm{pH}$ (slope $=1$ ) in the $\mathrm{pH}$ range of 6-10, suggesting $\mathrm{HO}^{-}$as a reactant. The rates of the same reactions in $\mathrm{D}_{2} \mathrm{O}$ have the same $\mathrm{pD}$ profile and reflect a solvent kinetic isotope effect (SKIE) of $\approx 8.5$. Glu376Gln+Glu99Gly-MCAD (studied to assess the role of Glu99 also present at the bottom of the active center cavity) has activities and activity profiles similar to those of Glu376Gln-MCAD. This excludes Glu99 as the active center base for Glu376Gln-MCAD catalysis. Proton inventories for the two phases of the dehydrogenation reaction were investigated at 4 and $25{ }^{\circ} \mathrm{C}$. The inventories at $25{ }^{\circ} \mathrm{C}$ reflect a SKIE of $\approx 4.5$; the profiles are "bowlshaped", in which a transition-state contribution predominates. The profiles for the $4{ }^{\circ} \mathrm{C}$ reaction are very unusual. That for the first phase can be analyzed on a two-step model with one step (80\% rate-limiting) having a conformational reorganization with an isotope effect of 90-100, from small isotope effects at many protein sites, and the other step (20\% rate-limiting) having an inverse isotope effect of ca. 2, characteristic of the reaction of hydroxide ion as a base. For the second phase, only a contribution from many protein sites with a KIE of $\approx 4.5$ is observed. The results are compatible with a very rigid active site framework that must undergo rearrangements for dehydrogenation to take place, and specifically to allow access of $\mathrm{HO}^{-}$, the reactant that must neutralize the $\mathrm{H}^{+}$abstracted from the $\alpha \mathrm{C}-\mathrm{H}$ substrate. The large isotope effects are attributed to the changes in state of several H-bonds that occur during the process.
\end{abstract}

Medium-chain acyl-CoA dehydrogenase $(\mathrm{MCAD})^{1}$ is a prominent member of the fatty acyl-CoA dehydrogenase family $(1,2)$. The latter encompasses nine members that differ in their preferences for the side chain of acyl-CoA substrates (2). MCAD is selective for substrates of medium chain length, preferring octanoyl- and decanoyl-CoA, and catalyzes their dehydrogenation to yield trans-enoyl-CoAs (Scheme 1). This reaction has been intensively studied over the past 20 years $(1-10)$ and is initiated by attack of the Glu376-COO ${ }^{-}$active center on the $\alpha \mathrm{C}-\mathrm{H}$ substrate (Scheme 1). The $\mathrm{p} K_{\mathrm{a}}$ of this function is lowered by some $10 \mathrm{p} K$ units upon binding to MCAD, mainly as a result of formation of two tight H-bonds of the thioester carbonyl at the active center (9). In addition, electronic ground-state interactions

\footnotetext{
$\dagger$ This work was supported in part by grants from the Deutsche Forschungsgemeinschaft (Gh 2/6-4) to S.G.

* To whom correspondence should be addressed. Phone: +497531 882291. Fax: +497531 882966. E-mail: sandro.ghisla@uni-konstanz.de.

$\doteqdot$ University of Kansas.

$\S$ University of Konstanz.

${ }^{1}$ Abbreviations: MCAD, human medium-chain acyl-CoA dehydrogenase; wtMCAD, wild-type MCAD; KIE, kinetic isotope effect; SKIE, solvent kinetic isotope effect.
}

Scheme 1: Dehydrogenation of the Acyl-CoA Substrate by $\mathrm{MCAD}^{a}$
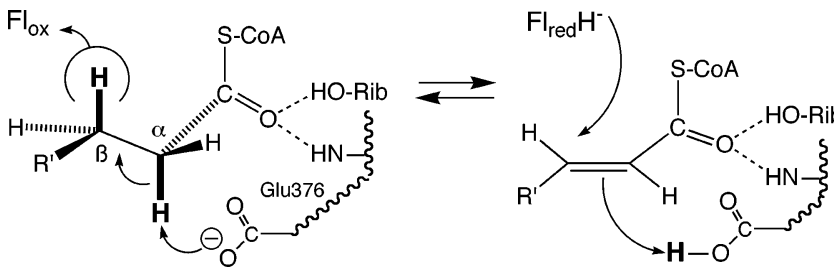

${ }^{a}$ See ref 2 for details of this reaction.

with the oxidized flavin contribute to this activation $(11,12)$. Glu376 was identified as the base initiating catalysis (13, 14) based on the effects induced by the Glu376Gln substitution (14). It should be noted that the nature of the position 376 functionality as such does not have a major effect on the activation of the acyl-CoA substrate, i.e., on the acidity of its $\alpha \mathrm{C}-\mathrm{H}$ group. Thus, the $\alpha \mathrm{C}-\mathrm{H} \mathrm{p} K_{\mathrm{a}}$ of substrate analogues bound to either wtMCAD or Glu376 MCAD is on the same order of magnitude $(10,15)$. Interestingly, within the ACAD family, the function of Glu376 can be assumed also by a different Glu residue that is placed topologically at the same position but lies on different segments of the protein chain $(12,16-18)$. A surprising finding emerging 
from the study of mutants was that the Glu376Gln mutant has an activity in the dehydrogenation reaction (Scheme 1) that is some 5 orders of magnitude lower than that of wtMCAD but has finite values (14). This activity has been confirmed by independent studies (19). Since it is unlikely that the amide group of Gln functions as a base abstracting a $\mathrm{H}^{+}$in the type of reaction depicted in Scheme 1, this residual activity has remained a puzzle. Its solution constitutes a mechanistic challenge that is expected to be important for understanding the means by which ACADs bring about catalysis. It should be noted that activity also remains in the case of replacement of Glu376 with other residues such as Gly, His, Cys, or Asp (20-22). This residual activity is thus probably not due to properties of the $G \ln 376$ group but is brought about by specific features of the MCAD active center.

In this context, it should also be noted that the active site of MCAD is characterized by several unusual properties. It has a pronounced hydrophobic character, this being a factor contributing to the considerably high $\mathrm{p} K_{\mathrm{a}}$ of $6-8$ of Glu376$\mathrm{COOH}$ (this value depending on the presence of ligands) $(9,10,23)$. The cofactor flavin is effectively shielded from solvent as reflected by the extremely low rate of oxygen reactivity of its reduced form in the presence of product (24). In the study presented here, we have attempted to uncover the features that bring about the unusual reactivity of Glu376MCAD mutants and to link this to the question of its general mechanism. During the study, we have come across some unexpected and unusual properties of MCAD that pertain to the access and exchange of solvent-borne $\mathrm{H}^{+} / \mathrm{HO}^{-}$at the active center and that we consider to be of general interest.

\section{EXPERIMENTAL PROCEDURES}

Instrumentation and Methods. Visible and ultraviolet spectra were recorded with a Kontron Uvikon 930 spectrophotometer. Experiments requiring a longer time frame required $4{ }^{\circ} \mathrm{C}$ since E376Q-MCAD has the tendency to develop turbidity or to reoxidize when incubated for $>30$ min at $25^{\circ} \mathrm{C}$. Anaerobic reactions were followed in Thunberg type cuvettes equipped with two side arms. Oxygen depletion was achieved by at least four flushing and evacuation cycles using $\mathrm{O}_{2}$-free argon in the presence of an oxygen scavenging system $(0.1 \mu \mathrm{M}$ glucose oxidase, $0.1 \mathrm{M}$ glucose, and 0.1 $\mu \mathrm{M}$ catalase, or $10 \mathrm{mM}$ L-Leu and $0.2 \mu \mathrm{M}$ L-amino acid oxidase) either directly in the solution or in a sidearm of the cuvette. Rapid reaction studies were conducted with a stopped-flow spectrophotometer with a $1.0 \mathrm{~cm}$ path length cell (25) and a diode array detector (J\&M Aalen), using BioKine. The instrument has a fastest acquisition time of 1 spectrum $/ 0.7 \mathrm{~ms}$ in the range of $300-650 \mathrm{~nm}$. In general, blocks of 120 spectra each were recorded for the first 100 ms and 1-2 s intervals and, for a third, variable length of time up to $5 \mathrm{~min}$. Stopped-flow experiments were conducted at $25{ }^{\circ} \mathrm{C}$. The concentrations mentioned are those of the reagents after mixing, i.e., 1/1 dilution, from the initially prepared solutions.

Materials and Enzymes. Ampicillin, HEPES, and TRIZMABASE were from Sigma. Glucose oxidase and catalase were from Boehringer Mannheim. L-Amino acid oxidase was obtained as described elsewhere (26). Ferricenium hexafluorophosphate (FcPF6, Aldrich) was prepared according to
Lehman et al. (27). The generation of the system for the expression of E376Q-MCAD and E376G-MCAD was described previously $(14,17)$. E376Q+E99G-MCAD was obtained by mutagenesis starting from the E376Q-MCAD gene (14). The expression of MCAD mutants was performed under conditions described previously (28) at a growth temperature of $28^{\circ} \mathrm{C}$ (host strain of Escherichia coli TG1). The enzyme was purified as described for similar mutants (28), and preparations were found to contain varying amounts of CoA persulfide that induces the typical green color (29); the green and yellow forms ("degreening") were separated with a hydroxyapatite column chromatography. Acyl-CoAs were prepared according to ref 30 from CoASH; the latter and FAD were from Waldhof (Düsseldorf, Germany). Used extinction coefficients were as follows: saturated acylCoAs, $\epsilon_{260}=15.4 \mathrm{mM}^{-1} \mathrm{~cm}^{-1}(31) ; \mathrm{FAD}, \epsilon_{260}=10.8 \mathrm{mM}^{-1}$ $\mathrm{cm}^{-1}(32)$.

Evaluation of Experimental Data. Data consisting of either time-resolved sequences of spectra or OD versus time profiles were evaluated with BioKine (Bio-Logic, Science Instruments SA) or SPECFIT/32 (Spectrum Software Associates) that is based on the algorithms described in ref 33 . Simulations were carried out with SPECFIT/32 as detailed in the Supporting Information. Equations used for fits of data points

$$
y=A_{\mathrm{o}} \pm A \mathrm{e}^{-k t} \pm \ldots
$$

where $A_{\mathrm{o}}$ is an initial value, $A$ is the extent of the absorbance changes, $k$ is the rate constant, and $t$ is time. The ellipsis denotes further terms of the same type used for multiexponential fits and \pm the either positive or negative sign of the term depending on whether a phase is increasing or decreasing.

$$
y=k_{(+)}[x /(K+x)]+k_{(-)}
$$

which is based on ref 34 , where $k_{(+)}$is the maximal forward rate constant, $k_{(-)}$the reverse rate constant, and $K$ the preceding dissociation equilibrium constant $\left[=k_{(-)} / k_{(+)}\right]$.

$$
y= \pm A \pm \log \left[1+\left(10^{-\mathrm{p} K}\right) / 10^{-\mathrm{pH}}\right] \pm \log (\ldots)
$$

which is based on ref 35 , where $A$ is a pH-independent value and the ellipsis can be a further, similar term for a different $\mathrm{p} K$.

\section{RESULTS}

Interaction of Glu376Gln-MCAD with the Substrate. The interaction of MCAD with acyl-CoA ligands can be affected by buffer composition and ionic strength as documented in various studies $(27,36,37)$. To minimize such effects, and on the basis of these studies, the buffer system described in the legend of Figure 1 was used, which is composed of low concentrations of cationic buffers together with a high salt concentration $(250 \mathrm{mM} \mathrm{KCl})$ to ensure a constant dielectric. Thus, a 20-fold variation of the concentration of specific buffer species does not affect observed rates significantly. In a general sense, these conditions were found to have the weakest effect on ligand interactions in specific experiments. The absorption spectrum of the mutant enzyme (Figure 1A) is essentially identical to that of wtMCAD (38) under similar 

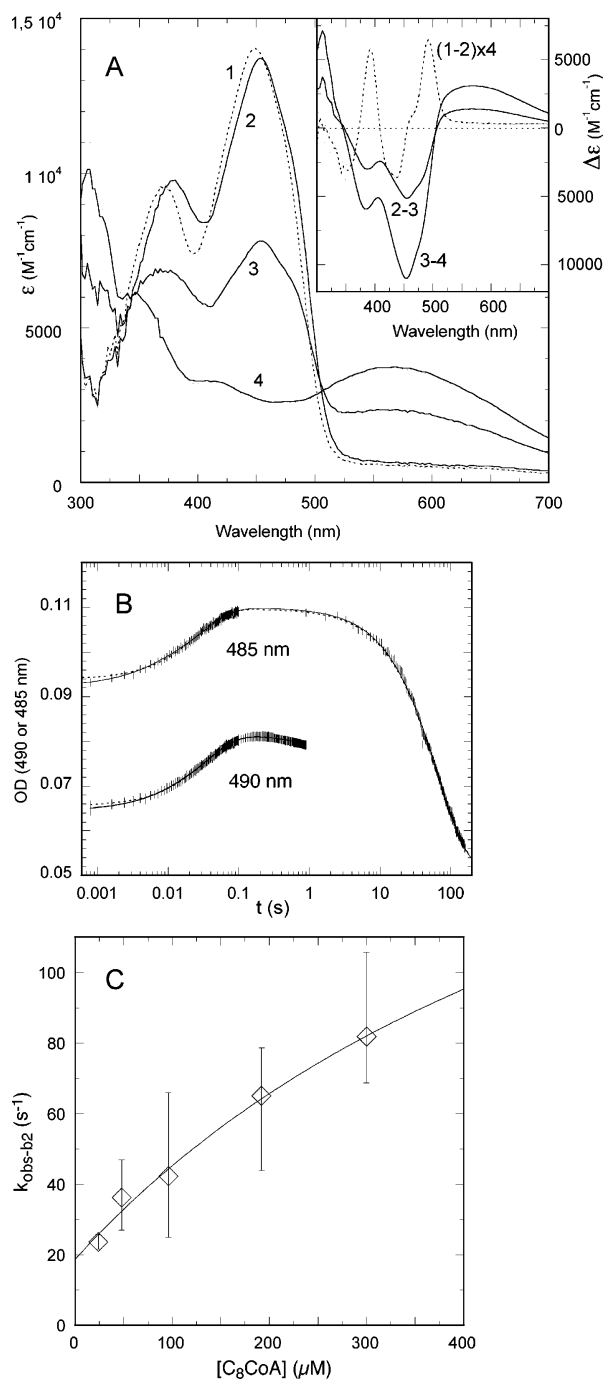

Figure 1: Binding of $\mathrm{C}_{8} \mathrm{CoA}$ to Glu376Gln-MCAD at $25^{\circ} \mathrm{C}$ and ensuing reactions. The spectra in panel A were recorded with the stopped-flow spectrophotometer (see Experimental Procedures for details). The enzyme, $12 \mu \mathrm{M}$ in Hepes, Tricine, Tris, and glycine (12.5 mM each), containing $250 \mathrm{mM} \mathrm{KCl} \mathrm{(pH} \mathrm{9.3)} \mathrm{was} \mathrm{reacted}$ with 8 equiv of $\mathrm{C}_{8} \mathrm{CoA}(96 \mu \mathrm{M}$ final concentration) in the same buffer at $25^{\circ} \mathrm{C}$. (A) Trace 1 is the spectrum of the uncomplexed enzyme before mixing. Traces $2-4$ are deconvoluted spectra of species occurring after mixing that were obtained with SPECFIT/ 32 and that correspond to a species formed in the dead time of the instrument (2), to an intermediate (3), and to a final species (4) in a corresponding sequence. The inset shows the differences between the aforementioned curves. Note that the difference spectrum (1 minus 2) does not exhibit long-wavelength absorption (corresponding to a CT band) or flavin reduction (no significant absorbance decrease in the $450 \mathrm{~nm}$ region). Such effects occur for the subsequent species ( 2 minus 3 and 3 minus 4 ). The rates for the three phases corresponding to conversion of the species are 39, 0.011 , and $0.003 \mathrm{~s}^{-1}$. (B) Time dependence of the absorbance at 485 and $490 \mathrm{~nm}$, i.e., at approximately one of the maxima of absorbance perturbation due to binding (see 1 minus 2 in the inset of panel A). The data points (|) for the 485 trace were fit using eq 1 with either a single (- - ) or double exponent $(-)$ for the ascending segment (from 0.0007 to $0.1 \mathrm{~s}$ ) and one exponent for the last (descending) segment (from 0.1 to $1 \mathrm{~s}$ ). Fits of $490 \mathrm{~nm}$ ascending data points, as for the 485 trace (rates for the two-exponent increase, 220 and $32 \mathrm{~s}^{-1}$; rate for the monoexponent increase, $35 \mathrm{~s}^{-1}$ ). (C) Dependence of $k_{\mathrm{obs}-\mathrm{b} 2}$, the rate reflecting $\mathrm{C}_{8} \mathrm{CoA}$ binding (conversion of species $1 \rightarrow 2$, panel $\mathrm{A}$ ), on $\mathrm{C}_{8} \mathrm{CoA}$ concentration. The data points $(\diamond)$ are the average from four to eight single measurements that were obtained with SPECFIT/32 (global wavelength analysis). The bars indicate the scatter of the single data points, and the line is the fit obtained using an algorithm based on eq 2 . conditions, suggesting minimal differences in the polarity at the active center. With wtMCAD, substrate binding cannot be studied directly since its rate is partially limiting and of the same order of magnitude as that of the subsequent dehydrogenation reaction. With the E376Q mutant, however, the rate of the latter is slower by some $4-5$ orders of magnitude; this mutant is thus ideally suited to investigation of binding. An assessment of the binding kinetics is also required for a proper study of the subsequent steps occurring with the E376Q mutant. Thus, binding of octanoyl-CoA was investigated with the stopped-flow instrument. Figure 1A shows that the interaction with substrate perturbs the spectrum of the oxidized flavin in a manner that is similar but not identical to that observed upon binding of a variety of neutral ligands to wtMCAD (39) [ligands that carry a negative charge and give rise to charge transfer absorptions induce different perturbations $(10,40,41)]$. It is noteworthy that the perturbations of the flavin spectrum signal a transition to a more hydrophobic environment as evidenced by the batochromic shift of the main absorption band, and its higher resolution (42). Binding can thus be followed on the basis of the difference spectra (curves 1 and 2) depicted in the inset of Figure 1A. The rates of the spectral perturbations are dependent on the concentration of substrate and follow the same kinetic pattern at all wavelengths. Figure 1B shows representative traces recorded around $490 \mathrm{~nm}$, one of the maxima of the mentioned difference spectra. The changes at these specific wavelengths are initiated by a rapid absorbance increase up to approximately $0.1 \mathrm{~s}$. This is followed by a much slower process, the beginning of the reduction phase (transition from difference spectra $(1-2)$ to spectra $(2-3)$ in Figure 1A, inset). The increase is not strictly monophasic. Under the specific conditions of Figure 1B, i.e., $100 \mu \mathrm{M} \mathrm{C}{ }_{8} \mathrm{CoA}$, at the onset of the reaction $5-10 \%$ of the changes occur at a rate $\left(220 \mathrm{~s}^{-1}\right.$ under the specific conditions) that is approximately 1 order of magnitude faster than that of the main phase of the absorbance increase. At higher $\mathrm{C}_{8^{-}}$ CoA concentrations, this minor phase cannot be observed; it was neglected for the purpose of the evaluation of rate constants. The dependence of the rate of this spectral perturbation on substrate concentration is shown in Figure 1C. This representation reflects a two-step process (34) as represented by segments denoted by b1 and b2 in Scheme 2 . The first step $\left(k_{\mathrm{b} 1} \gg 200 \mathrm{~s}^{-1}\right)$ reflects very rapid formation of a first equilibrium $\mathrm{E}_{\mathrm{ox}}--\mathrm{S}$ complex $\left(K_{\mathrm{b} 1}=680 \pm 170\right.$ $\mu \mathrm{M})$. In the second equilibrium $\left(K_{\mathrm{b} 2}\right)$, the $\mathrm{E}_{\mathrm{ox}}--\mathrm{S}$ complex is converted to the $\mathrm{E}_{\mathrm{ox}}-\mathrm{S}$ complex. The value of $k_{\mathrm{b} 2}$ at saturation is estimated from Figure $1 \mathrm{C}$ to be $210 \pm 35 \mathrm{~s}^{-1}$, while the ordinate intercept is the reverse rate constant $k_{-\mathrm{b} 2}$ $\left(19 \pm 1 \mathrm{~s}^{-1}\right)$. This yields an equilibrium constant $K_{\mathrm{b} 2}$ of 0.09 $\pm 0.02 \mathrm{M}$ and an overall binding constant $K_{\mathrm{d}, \mathrm{b}}\left(K_{\mathrm{b} 1} K_{\mathrm{b} 2}\right)$ of $60 \pm 20 \mu \mathrm{M}$ under the conditions of Figure $1 \mathrm{C}$. It should be stated that this analysis is not affected by subsequent steps since these are slower by $>4$ orders of magnitude (depending on $\mathrm{pH}$ ).

These steps are designated with the subscript $r$ (Scheme $2, k_{\mathrm{r}}$ ) since they involve dehydrogenation/flavin reduction, and the corresponding spectral changes are followed in a conventional spectrophotometer as depicted in Figure 2A for the reaction at $4{ }^{\circ} \mathrm{C}$. At this temperature, binding induces more pronounced spectral perturbations compared to those at $25^{\circ} \mathrm{C}$ (compare insets of Figures $1 \mathrm{~A}$ and $2 \mathrm{~A}$ ); however, 
Scheme 2: Minimal Kinetic Scheme Describing Steps and Species Involved in the Reaction of E376Q-MCAD with the Substrate $\mathrm{C}_{8} \mathrm{CoA}^{a}$

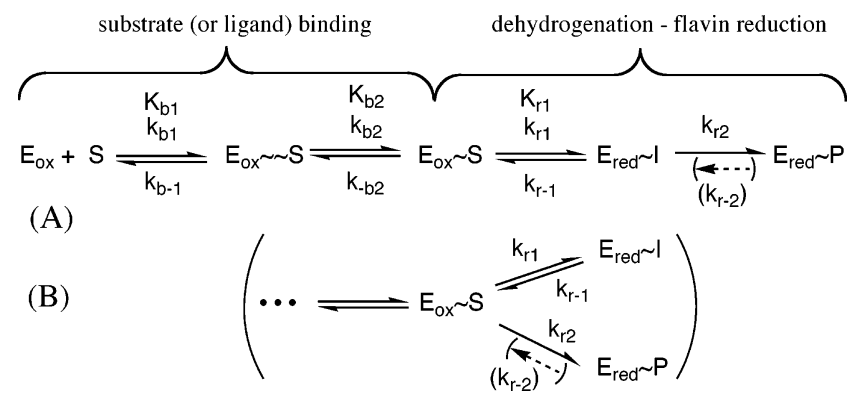

${ }^{a}$ Processes describing substrate (ligand) binding carry the subscript $\mathrm{b}$ and those involving reduction of the flavin cofactor the subscript $\mathrm{r}$. $\mathrm{E}_{\mathrm{ox}}--\mathrm{S}$ and $\mathrm{E}_{\mathrm{ox}}-\mathrm{S}$ are different substrate complexes of the oxidized enzyme formed sequentially. $\mathrm{E}_{\text {red }}-\mathrm{I}$ and $\mathrm{E}_{\text {red }}-\mathrm{P}$ are an intermediate and the final species observed during flavin reduction, respectively, where $\mathrm{E}_{\mathrm{red}}-\mathrm{P}$ is the complex of the reduced enzyme with octenoylCoA. It should be noted that $\mathrm{E}_{\mathrm{red}}-\mathrm{I}$ is a species to which no physical structure can be attributed unequivocally on the basis of kinetic or spectroscopic data alone. These data are compatible with the presence of an equilibrium mixture $\left[\mathrm{E}_{\mathrm{ox}}-\mathrm{S} \Leftrightarrow \mathrm{E}_{\mathrm{red}}-\mathrm{P}^{*}\right]$, where $\mathrm{E}_{\mathrm{red}}-\mathrm{P}^{*}$ is spectrally similar to $\mathrm{E}_{\mathrm{red}}-\mathrm{P}$ but behaves in a manner kinetically different from that of $\mathrm{E}_{\mathrm{red}}-\mathrm{P}$, where $k_{\mathrm{r} 1}$ and $k_{\mathrm{r}-1}>k_{\mathrm{r} 2} \gg k_{\mathrm{r}-2}$, and where this equilibrium mixture is displaced toward $\mathrm{E}_{\mathrm{red}}-\mathrm{P}$ via $k_{\mathrm{r} 2}$. (A) and (B) refer to alternative kinetic sequences occurring sequentially or in parallel.

at both temperatures, no reduction of the flavin has occurred up to the point in time for the registration of spectra (2) (Figures 1 and 2). These spectra are thus attributed to the enzyme-substrate complexes $\left(\mathrm{E}_{\mathrm{ox}}-\mathrm{S}\right.$, Scheme 2$)$ that occur at these temperatures before dehydrogenation ensues and can be used for simulation purposes (see the Supporting Information). The ensuing spectral changes in Figure 2A (traces 2-7) correspond to reduction of the oxidized flavin and lead isosbestically to a species (6) with a spectrum very similar to that of the reduced enzyme-octenoyl-CoA complex described for wtMCAD (43). The course of the reduction reaction consists of two phases of similar extents with rates that differ by a factor of 3-10 depending on the conditions. The observed $k_{\mathrm{obs}-\mathrm{r} 1}$ and $k_{\mathrm{obs}-\mathrm{r} 2}$ rates of the two phases exhibit saturation behavior (Figure $2 \mathrm{~B}$ ) reflecting an apparent $K_{\mathrm{d}}$ of $30-40 \pm 20 \mu \mathrm{M}$. This value, although lower, compares with the equilibrium constant $K_{\mathrm{d}, \mathrm{b}}(60 \pm 20 \mu \mathrm{M})$ obtained from the kinetic experiments depicted in Figure 1, which were conducted at $25{ }^{\circ} \mathrm{C}$. The extent of reduction encompassing both phases also is dependent on the concentration of $\mathrm{C}_{8^{-}}$ CoA as shown in Figure 3. Thus, when [E376Q-MCAD] $\approx$ $\left[\mathrm{C}_{8} \mathrm{CoA}\right] \approx 10^{-5} \mathrm{M}$, approximately $50 \%$ reduction is observed and the $\mathrm{C}_{8} \mathrm{CoA}$ concentration dependence of the reduction extent reflects an interaction constant of $\sim 15 \mu \mathrm{M}$. This value should reflect the combination of all steps, i.e., $K_{\mathrm{b} 1}, K_{\mathrm{b} 2}$, and $K_{\mathrm{r} 1}+K_{\mathrm{r} 2}$ (Scheme 2). Importantly, this behavior demonstrates that steps $K_{\mathrm{r} 1}$ and $K_{\mathrm{r} 2}$ of Scheme 2 must be reversible, albeit at very slow rates. Attainment of a similar, substrate concentration-dependent equilibrium was observed also at pH 9 (not shown), suggesting that the effect is not $\mathrm{pH}$-dependent. When experiments were carried out with a $>5$-fold substrate molar excess, the extent of formation of the reduced enzyme-product complex, as reflected by its charge transfer absorption in the 550-600 nm region, becomes smaller. This is attributed to the exchange of product $\mathrm{P}$ with excess substrate in the reduced enzyme-
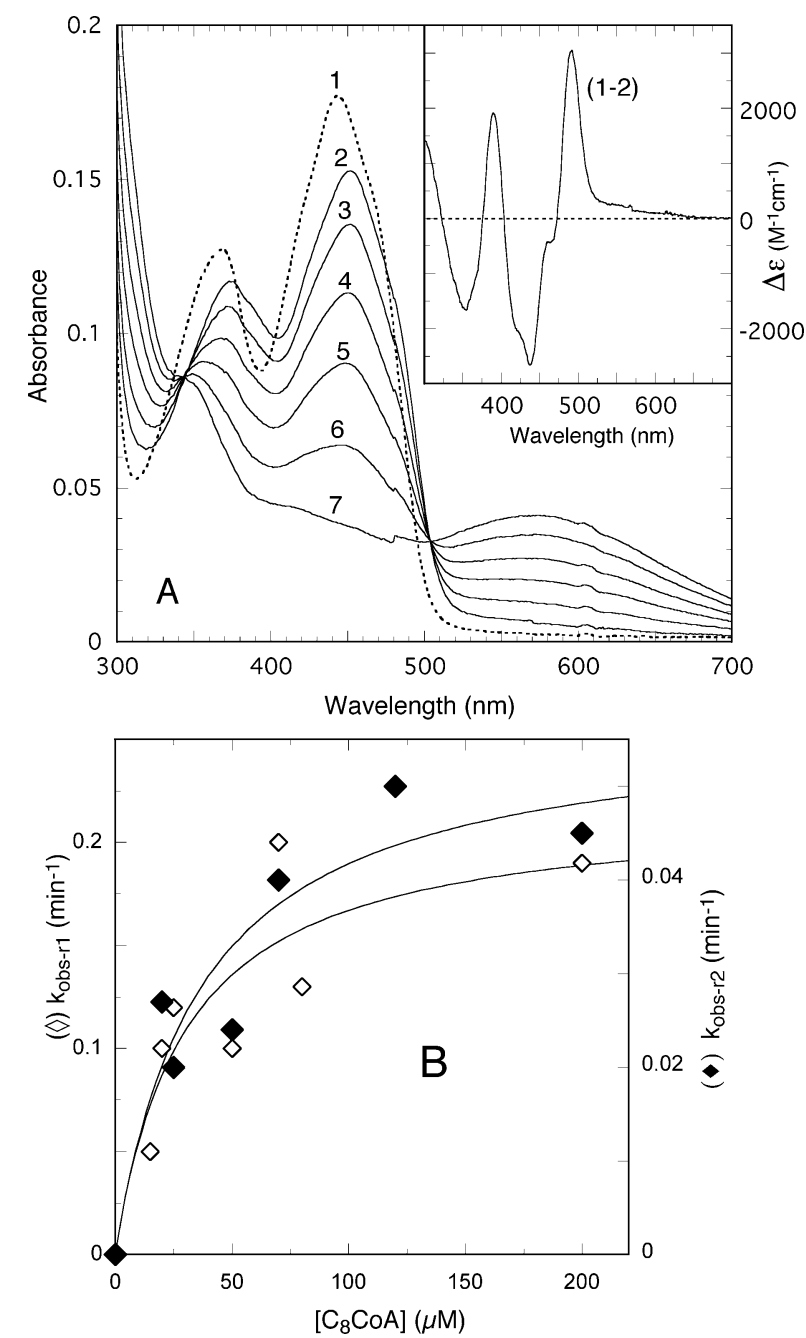

FIGURE 2: Interaction of $\mathrm{C}_{8} \mathrm{CoA}$ with Glu376Gln-MCAD at $4{ }^{\circ} \mathrm{C}$. Glu376Gln-MCAD $(12 \mu \mathrm{M})$ was in Hepes, Tricine, Tris, and glycine (12.5 mM each) containing $250 \mathrm{mM} \mathrm{KCl}(\mathrm{pH} 9.25)$. The enzyme was reacted with $96 \mu \mathrm{M} \mathrm{C}_{8} \mathrm{CoA}$ under anaerobic conditions (1.0 mL of Thunberg type optical cuvettes, $10 \%$ glycerol, $10 \mathrm{mM}$ glucose, and $0.2 \mu \mathrm{M}$ glucose oxidase), and the course of the reaction was followed at $4{ }^{\circ} \mathrm{C}$ by repetitive scanning in a conventional spectrophotometer. (A) Curve 1 is the enzyme before addition of substrate. Curves $2-7$ are representative curves obtained after 12 , $76,236,540,1104$, and $3588 \mathrm{~s}$, respectively. The course of the reaction from curve 2 to 7 is biphasic (not shown; compare to Figure 4). The inset shows the difference spectrum between the starting species 1 and curve 2 . Note the similarity in shape with the dashed curve in the inset of Figure 1. (B) $\mathrm{C}_{8} \mathrm{CoA}$ concentration dependence of the rates of the fast $\left(k_{\mathrm{obs}-\mathrm{r} 1}\right)$ and slow $\left(k_{\mathrm{obs}-\mathrm{r} 2}\right)$ phases of flavin reduction. The rates were obtained as detailed in the text. The traces (一) are fits based on the saturation equation (60).

product complex $\left(\mathrm{E}_{\mathrm{red}}-\mathrm{P}\right)$, which is also observed with wtMCAD (7). On the basis of these findings and the observation that when $\left[\mathrm{C}_{8} \mathrm{CoA}\right] \gg$ [E376Q-MCAD] a decrease of the reaction rates also occurs, most kinetic studies presented in this work were carried out with $80 \mu \mathrm{M} \mathrm{C} \mathrm{C}_{8} \mathrm{CoA}$ $(\approx 8[\mathrm{E} 376 \mathrm{Q}-\mathrm{MCAD}])$.

The spectral perturbations occurring upon substrate binding at $25{ }^{\circ} \mathrm{C}$ (Figure $1 \mathrm{~A}$, inset) and $4{ }^{\circ} \mathrm{C}$ (Figure 2A, inset) are similar but not identical. This pertains in particular to the ratios of the peaks in the difference spectra and the corresponding extinction coefficients. The overall spectral course of the ensuing flavin reduction reaction is similar to that observed with wtMCAD (43), the important difference 


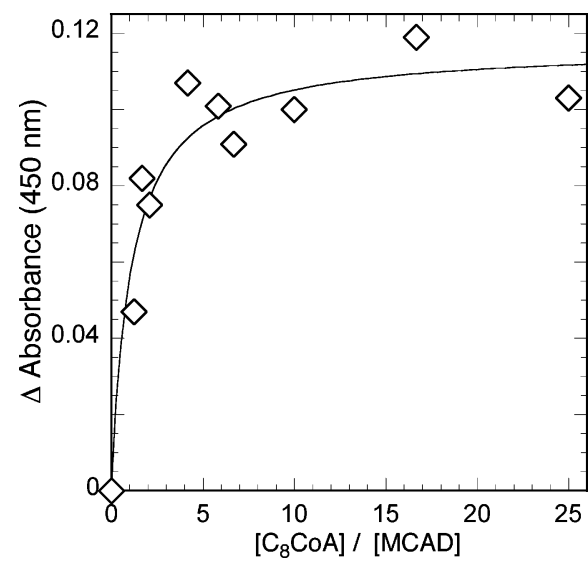

FIGURE 3: Dependence of the extent of flavin reduction of Glu376Gln-MCAD on $\mathrm{C}_{8} \mathrm{CoA}$ concentration. Glu376Gln-MCAD $(12 \mu \mathrm{M}, \mathrm{pH} 7.6)$ was tested under anaerobic conditions $(1.0 \mathrm{~mL}$ of Thunberg type optical cuvettes, $50 \mathrm{mM} \mathrm{KP}, 0.3 \mathrm{mM}$ EDTA, $10 \%$ glycerol, $10 \mathrm{mM}$ glucose, and $0.2 \mu \mathrm{M}$ glucose oxidase) and at 4 ${ }^{\circ} \mathrm{C}$. Under the these conditions and in contrast to those of Figure 2 , an oxygen scavenger is required due to the longer reaction times (since $\left[\mathrm{C}_{8} \mathrm{CoA}\right] \leq[\mathrm{MCAD}]$ ) and to avoid the concurring reoxidation of the reduced enzyme. Aliquots of a $1 \mathrm{mM}$ solution of $\mathrm{C}_{8} \mathrm{CoA}$ were added to the system to yield the indicated concentrations, and the absorbance decrease at $450 \mathrm{~nm}$ was followed until it approached completion. The data points are the $\triangle \mathrm{OD}$ values corresponding to the difference between curve 1 in Figure 2A and the last curve recorded in analogous experiments.

being that the rates are some 5 orders of magnitude slower. A further difference, compared to wtMCAD, is the effect of oxygen on some apparent rates of reduction. Specifically and depending on the type of MCAD mutant, the $\mathrm{pH}$ and temperature of the second phase, $k_{\mathrm{r} 2}$, can be 2-3-fold lower under aerobic conditions compared to those under anaerobic ones. This is attributed simply to competing reoxidation with oxygen that becomes important when either the rate of reoxidation is comparatively fast (high temperature or an effect of a specific mutation) or the rate of the second phase of reduction is very slow, i.e., $t_{1 / 2} \geq 10 \min (24)$. Thus, in cases where competition by oxygen reoxidation becomes relevant, measurements were carried out anaerobically as specified in the legends of the corresponding figures.

Analysis of Data and Estimation of Rate Constants. As discussed above, and in accordance with studies by others carried out with substrate analogues $(7,44-46)$, the interaction of substrate with MCAD is a multistep process (Scheme 2). The separation in kinetic terms of rates involving binding (subscript b, Scheme 2) from those that involve substrate dehydrogenation and concomitant flavin reduction (subscript $\mathrm{r}$ ) is $\geq 1$ order of magnitude and thus much better in this case compared to wtMCAD. With wtMCAD, flavin reduction (rate constants $k_{\mathrm{r}}$ ) in general consists of two phases (6, $7,47)$. The basic problems and difficulties inherent to the evaluation of such situations have been pointed out previously $(6,7)$ and have also been examined recently with respect to their fundamental aspects by Fisher et al. $(48,49)$ and Palfey and Fagan (50).

Kinetic data from experiments conducted at $25^{\circ} \mathrm{C}$ were first fitted using an equation with one or two exponential terms (eq 1). The time required for experiments such as those in Figure 6 can vary by up to 3 orders of magnitude. Thus, at this temperature, problems with enzyme stability and development of turbidity can arise, in particular when the period of data collection exceeds $10 \mathrm{~h}$ as is the case for experiments conducted at low pH (Figure 6). Therefore, in such cases, data points could be obtained only for the first (observable) rate of enzyme reduction, $k_{\mathrm{r}}$, and by monoexponential fitting (eq 1). $k_{\mathrm{b}}$ steps (substrate binding, Scheme 2) are much faster at $25^{\circ} \mathrm{C}$ compared to subsequent $k_{\mathrm{r}}$ steps; they do not influence analysis of the latter. The same sets of data were then examined by the simulation procedure described below and in the Supporting Information. The resulting rates $k_{\mathrm{r} 1}$ and $k_{\mathrm{r} 2}$ are depicted in Figures 6 and 8. It is important to note that while the absolute values of rate constants obtained from either fitting or simulation can vary considerably, the corresponding KIEs do not under these conditions.

The spectral course of the reaction at $4{ }^{\circ} \mathrm{C}$ is shown exemplarily in Figure 2A and also consists of two main phases of flavin reduction that are designated $k_{\mathrm{r} 1}$ and $k_{\mathrm{r} 2}$. When the spectra are recorded at a fixed wavelength of 450 $\mathrm{nm}$ and at low $\mathrm{C}_{8} \mathrm{CoA}$ concentrations, an initial, minor absorbance change can be detected that is much faster and corresponds to the transition from spectrum 1 to 2 in Figure $2 \mathrm{~A}$; it reflects the final part of the absorbance changes occurring during substrate binding $\left(k_{\mathrm{b} 2}\right.$; see also rapid kinetic experiments described above and in the legend of Figure 1). Also in this case, this phase does not affect the evaluation of subsequent processes since the separation of rates is $>10$. The rates of the reduction phases $k_{\mathrm{r} 1}$ and $k_{\mathrm{r} 2}$ are separated by factors of 3-10, the exact ratio depending on the conditions and specifically on the KIEs associated with steps $k_{\mathrm{r} 1}$ and $k_{\mathrm{r} 2}$. For this reason, and since $k_{\mathrm{r} 1}$ is reversible (see the dependence of formation of the $\mathrm{E}_{\mathrm{red}}-\mathrm{P}$ complex from $\mathrm{C}_{8} \mathrm{CoA}$ described above and in the legend of Figure 3), a borderline situation occurs $(7,48,49)$. As discussed elsewhere, in such situations the attribution of an exponential apparent " $k$ " term to a specific kinetic step or mechanistic event is not possible $(7,48,49)$. In view of this, and to obtain rate constants for steps $k_{\mathrm{r} 1}$ and $k_{\mathrm{r} 2}$, we have carried out a comprehensive simulation analogous to that reported previously for the reaction of wtMCAD with the substrate butyrylCoA $(7,48)$ and as outlined in the Supporting Information. Examples of the simulation results are shown in Figure 4 for 0,45 , and $96 \% \mathrm{D}_{2} \mathrm{O}$, and the corresponding rates are listed in Table 1. Simple visual inspection of Figure 4 evidences a conspicuous SKIE, the magnitude of which varies somewhat with the progress of the reaction but is on the order of $6-8$. The panel representing the residuals shows that the deviation of experimental data and simulation trace is $<2 \%$ and demonstrates the absence of substantial systematic errors. It also yields a visual impression of the magnitude of the errors inherent to this type of experiment and of the quality of the simulation. Similar results were obtained throughout the $0-100 \% \mathrm{D}_{2} \mathrm{O}$ range $(n$ fraction $\mathrm{D}$, Figures 4, 8, and 9).

The traces for 0,45 , and $96 \% \mathrm{D}_{2} \mathrm{O}$ and at $4{ }^{\circ} \mathrm{C}$ (Figure 4) and at the other " $n$ " values (Figure 9) were simulated satisfactorily on the basis of Scheme 2A using a constant overall $K_{\mathrm{d}}$ (i.e., $K_{\mathrm{b} 1} K_{\mathrm{b} 2}$ ) of $1.9 \times 10^{-4} \times 0.03=6 \times 10^{-6}$ M. Those for $25{ }^{\circ} \mathrm{C}$ required an overall $K_{\mathrm{d}}$ of $2-3 \times 10^{-5}$ $\mathrm{M}$. The approximately 4-fold difference is attributed to tighter binding at the lower temperature. The values for the single binding steps $\left(k_{\mathrm{b}}\right)$ required for simulation could be held constant for the two temperatures. This suggests that an IE 


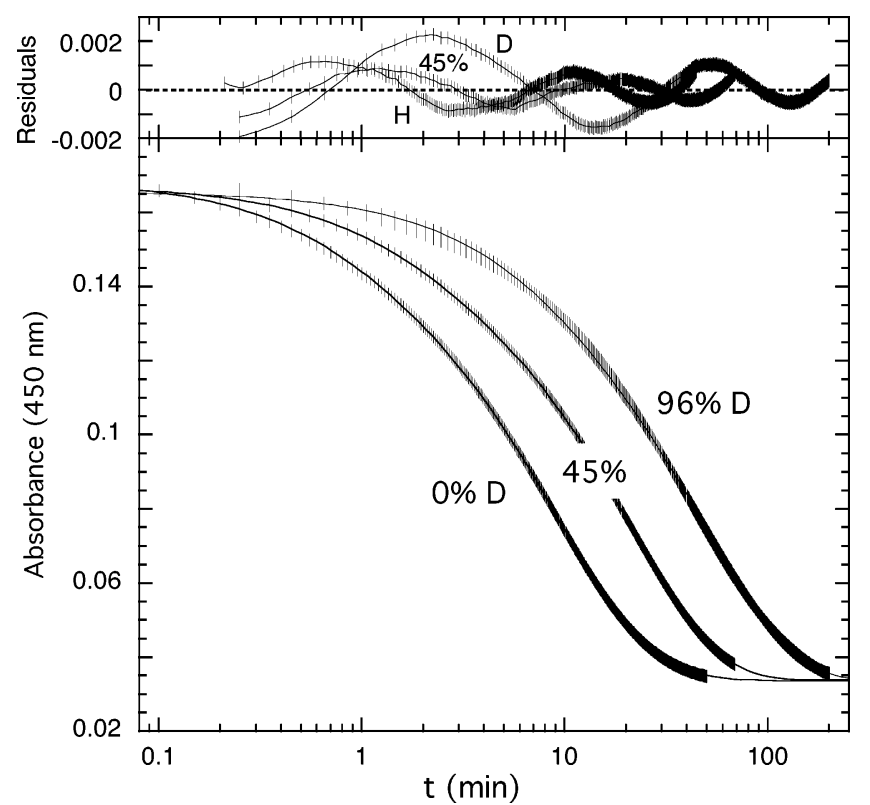

FIGURE 4: Analysis of Glu376Gln-MCAD absorbance changes vs time for the reduction of the enzyme flavin as a function of $n$. The reactions were carried out as outlined in the legend of Figure 2, at $4{ }^{\circ} \mathrm{C}$ and $\mathrm{pH} 9.25$, the difference being that the absorbance changes were recorded at a single wavelength $(450 \mathrm{~nm})$. Vertical bars represent the single data points. The curves (-) are the results of simulations carried out using SPECFIT/32, and based on Scheme 2 (see the text and Supporting Information for details). The data and trace for $45 \% \mathrm{D}$ were expanded by $6 \%$ and normalized to the same starting point as the other traces for a better comparison. The top of the figure shows the residuals. The parameters obtained from this analysis are listed in Table 1.

Table 1: Selected Parameters Obtained from Analysis of Kinetic Traces of the Reaction of Glu376Gln-MCAD with $\mathrm{C}_{8} \mathrm{CoA}^{a}$

\begin{tabular}{ccccccc}
\hline & \multicolumn{2}{c}{ substrate binding } & & \multicolumn{3}{c}{$\begin{array}{c}\text { flavin reduction/substrate } \\
\text { dehydrogenation }\end{array}$} \\
\cline { 2 - 3 } \cline { 5 - 7 }$n\left(\% \mathrm{D}_{2} \mathrm{O}\right)$ & $K_{\mathrm{b} 1}(\mathrm{M})$ & $K_{\mathrm{b} 2}(\mathrm{M})$ & & $\begin{array}{c}k_{\mathrm{r} 1} \\
\left(\mathrm{~min}^{-1}\right)\end{array}$ & $\begin{array}{c}k_{\mathrm{r}-1} \\
\left(\mathrm{~min}^{-1}\right)\end{array}$ & $\begin{array}{c}k_{\mathrm{r} 2} \\
\left(\mathrm{~min}^{-1}\right)\end{array}$ \\
\hline 0 & $1.9 \times 10^{-4}$ & 0.03 & & 0.68 & 0.27 & 0.16 \\
45 & & & & 0.4 & 0.17 & 0.075 \\
96 & & & 0.054 & 0.009 & 0.025 \\
\hline
\end{tabular}

${ }^{a}$ See Scheme 2 for attribution of single kinetic steps. The reported values are for the examples of experimental and simulation traces in Figure 4. $K_{\mathrm{b}}$ and $k_{\mathrm{r}}$ steps are defined in Scheme 2. Conditions were as defined in the legend of Figure 4 , at $4{ }^{\circ} \mathrm{C}$ and pL 9.25.

on binding, if present, is small $(<1.1)$. Comparison of the standard deviation and sum of squares parameters listed in Table 4 (Supporting Information) for simulations without and with a finite $k_{\mathrm{r}-1}$ shows consistently better values for the latter case. The occurrence of an effective reversibility (equilibrium) for the $K_{\mathrm{r}}$ steps is also required by the dependence of the extent of reduction on the substrate concentration (see above and Figure 3). In contrast to this, $k_{\mathrm{r} 2}$ can be treated as being irreversible for simulation purposes since $k_{\mathrm{r}-2} \ll k_{\mathrm{r} 2}$. This follows from the observation that at very long reaction times ( $t>1 \mathrm{~h}$ ) enzyme reduction goes to completion in the presence of a small (ca. 8-fold) excess of $\mathrm{C}_{8} \mathrm{CoA}$, i.e., that in the final spectra the contribution of $\mathrm{E}_{\mathrm{ox}}$ is practically absent (see Figure $2 \mathrm{~A}$, trace 6 ). Rates $k_{\mathrm{r} 1}$ and $k_{\mathrm{r} 2}$ obtained from simulations of the $4{ }^{\circ} \mathrm{C}$ kinetic data are significantly larger (up to 10-fold) compared to those obtained from three-exponential fits (Table 4 of the Sup-

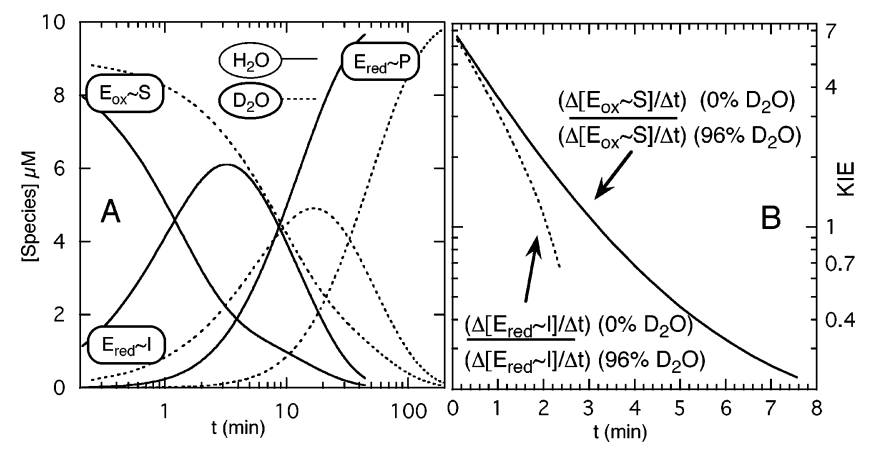

FIGURE 5: Time course of concentrations of species occurring during the substrate reduction of Glu376Gln-MCAD flavin and determination of $\operatorname{tKIE}_{x}^{0}$. (A) Time profiles are shown for species that undergo redox transformations and for $\mathrm{H}_{2} \mathrm{O}$ and $\mathrm{D}_{2} \mathrm{O}$ as the solvent. The data are from analysis as described in the legend of Figure 4 and in the text. (B) Determination of the KIE of the disappearance of the $\mathrm{E}_{\mathrm{ox}}-\mathrm{S}$ intermediate on the appearance of the $\mathrm{E}_{\mathrm{red}}-\mathrm{I}$ species according to the method of Fisher et al. $(48,49)$.

porting Information). This is due to the fact that the reverse $k_{\mathrm{r}-1}$ step is ignored in the latter procedure. In agreement with the principle of microscopic reversibility, the shape of the $n$ dependence of $k_{\mathrm{r}-1}$ (not shown) is comparable to that of $k_{\mathrm{r} 1}$ and is compatible with the absence of a significant KIE on the equilibrium $K_{\mathrm{r} 1}=k_{\mathrm{r} 1} / k_{\mathrm{r}-1}(\approx 5)$. However, in view of the scatter of the data points that is relatively much larger compared to that of $k_{\mathrm{r} 1}$ and $k_{\mathrm{r} 2}$, a further analysis of $k_{\mathrm{r}-1}$ data does not appear to be appropriate. A simulation of $k_{\mathrm{r} 1}$ can be performed also on the basis of a kinetic scheme in which $k_{\mathrm{r} 1}$ and $k_{\mathrm{r} 2}$ occur in parallel and branch at the locus of the $\mathrm{E}_{\mathrm{ox}}-\mathrm{S}$ complex (Scheme 2B). This case, however, requires that $k_{\mathrm{r}-1}$ be greater than $k_{\mathrm{r} 1}$; it is less accurate with respect to the extinction coefficient of the $E_{\text {red }}-I$ complex and yields overall simulations of inferior quality. This suggests that the sequential model depicted in Scheme 2A is a better description of the situation, although different mechanisms cannot be excluded. A similar conclusion was reached earlier for the reaction of wtMCAD with butyrylCoA (7).

Time Course of Concentrations of Involved Species and Solvent Isotope Effects. A further advantage of an evaluation based on simulation (SPECFIT/32) is that it yields the time course of the concentrations of the species of Scheme 2. This is displayed in Figure 5A for those that are involved in redox changes. Visual inspection of these profiles shows that the half-times of disappearance of the $\mathrm{E}_{\mathrm{ox}}-\mathrm{S}$ complex and the peak of maximal concentration of the intermediate $\mathrm{E}_{\text {red }}-\mathrm{I}$ species, which is formed concomitantly with dehydrogenation, differ by 7-12 min. This is consistent with the conspicuous SKIEs already apparent from the plot of the original traces (Figure 4). Application of the approach recently described by Fisher et al. $(48,49)$ then allows the estimation of the time dependence of the KIE and of $\mathrm{KIE}^{0}$, i.e., the KIE at time zero. This is the algebraic product of the intrinsic KIEs of the forward rate constants of all steps preceding formation of the $\mathrm{E}_{\mathrm{ox}}-\mathrm{S}$ complex and including that of its conversion to the $\mathrm{E}_{\mathrm{red}}-\mathrm{I}$ complex (48). Specifically for the analysis shown in Figure $5 \mathrm{~B}$, this yields a $\mathrm{KIE}^{0}$ of $\approx 7$. It should also be noted that Figure 5B shows the analysis based on the observation of the disappearance of the $\mathrm{E}_{\mathrm{ox}}-\mathrm{S}$ complex and that of the appearance of the $\mathrm{E}_{\text {red }}-\mathrm{I}$ complex. These extrapolate to essentially the same $\mathrm{KIE}^{0}$ (as they 


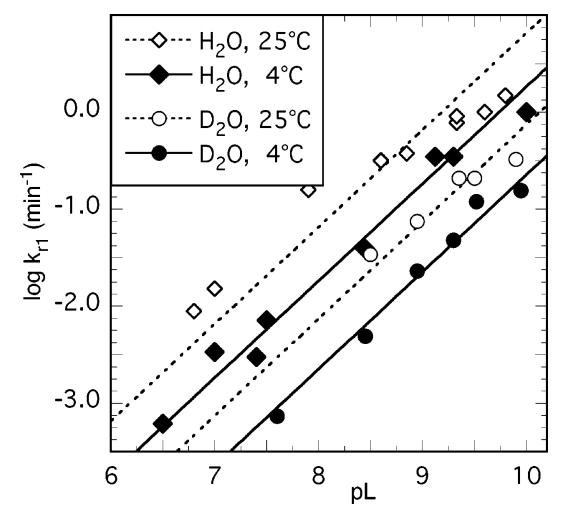

FIGURE 6: $\mathrm{pH}$ dependence of the rates of Glu376Gln-MCAD flavin reduction in $\mathrm{H}_{2} \mathrm{O}$ or $\mathrm{D}_{2} \mathrm{O}$. The reactions were conducted as described in the legend of Figure 2 either in $\mathrm{H}_{2} \mathrm{O}$ or in $98 \% \mathrm{D}_{2} \mathrm{O}$ buffers. Reactions at $25^{\circ} \mathrm{C}$ were conducted under anaerobic conditions (see the legend of Figure 3). For reactions in $98 \% \mathrm{D}_{2} \mathrm{O}$ buffers, a concentrated enzyme solution was diluted into $\mathrm{D}_{2} \mathrm{O}$ buffer. The $\mathrm{pL}$ for $\mathrm{D}_{2} \mathrm{O}$ solutions is $\mathrm{pH}_{\mathrm{obs}}+0.4$. The data points are for the first phase of enzyme flavin reduction and were obtained as detailed in the text. The traces are the fits obtained with eq 7 .

should) since they reflect the same kinetic steps (Scheme 2 ). The results of this analysis correspond very nicely to the predictions of the theoretical treatment discussed recently by Fisher's group $(48,49)$, in particular with respect to the decrease in the KIE with time.

pH Dependence of Reduction of Glu376Gln-MCAD with Substrate and Solvent Deuterium KIEs. Since substrate dehydrogenation does require dissociation of $\mathrm{H}^{+}$from the substrate $\alpha \mathrm{C}-\mathrm{H}$ in the absence of a specific base (see the introductory section), we anticipated that this would require involvement of solvent or $\mathrm{HO}^{-}$. The rates of enzyme reduction were thus studied in the accessible $\mathrm{pH}$ range of 6.5-10, and Figure 6 depicts this dependence of $k_{\mathrm{r} 1}$ with $\mathrm{H}_{2} \mathrm{O}$ or $\mathrm{D}_{2} \mathrm{O}$ as the solvent and at 4 and $25^{\circ} \mathrm{C}$. Due to problems related to enzyme instability at $25{ }^{\circ} \mathrm{C}$ (see also the discussion above), no reliable data could be obtained when the $t_{1 / 2}$ of either $k_{\mathrm{r} 1}$ or $k_{\mathrm{r} 2}$ exceeded $1 \mathrm{~h}$. Thus, for a majority of cases at $25^{\circ} \mathrm{C}$, only $k_{\mathrm{r} 1}$ values could be estimated, and these are plotted in Figure 6. The dependence demonstrates that the $k_{\mathrm{r} 1}$ rate increases with $\mathrm{HO}^{-}$concentration up to $\mathrm{pH} 10$. This increase is linear with a slope of 1 for the 4 ${ }^{\circ} \mathrm{C}$ data and for both $\mathrm{H}_{2} \mathrm{O}$ and $\mathrm{D}_{2} \mathrm{O}$ reflecting a constant KIE of $\sim 8$. Since the reaction is phenomenologically first order in $\mathrm{HO}^{-}$ion (Figure 6) and no sign of a decrease in the rate corresponding to an ionization is seen up to $\mathrm{pH} 9$, the $\mathrm{pK}$ shift of specific functional groups should not come into the picture, at least in this $\mathrm{pH}$ range. The $25{ }^{\circ} \mathrm{C}$ data show a "falloff" tendency above $\mathrm{pH} 9.5$, and thus, the occurrence of a "break" at $\mathrm{pH} \geq 10$ could be inferred. However, this is observed for both $\mathrm{H}_{2} \mathrm{O}$ and $\mathrm{D}_{2} \mathrm{O}$ and could have an origin that cannot be interpreted on the basis of the data presented here that show increasing scatter at high $\mathrm{pH}$.

pH Dependence of the Reduction of Glu376Gly- and Glu376Gln+Glu99Gly-MCAD with $C_{8} C o A$. This study was carried out (a) to assess the possible role in $\alpha \mathrm{C}-\mathrm{H}$ proton abstraction of Glu99, a group with potential base functionality that is also present at the bottom of the active center (5I) and (b) to gain information about whether the activity observed with the Glu376Gln mutant is specific to the 376Gln amide group itself. The enzyme flavin reduction rates for these mutants were measured as described above for

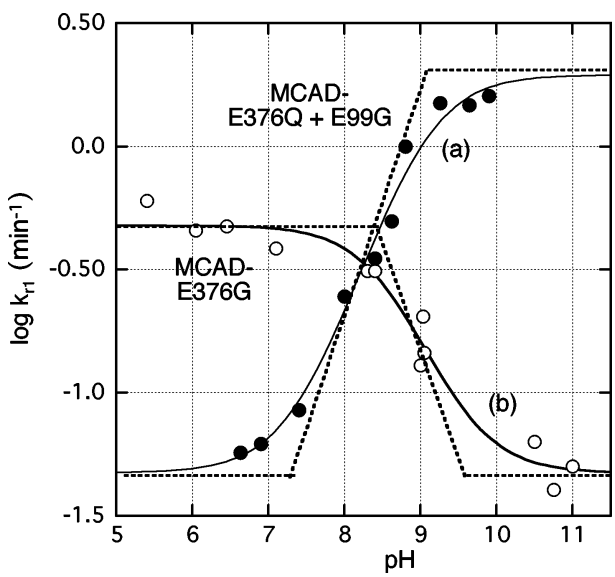

FIGURE 7: $\mathrm{pH}$ dependence of flavin reduction rates for Glu376Gln+Glu99Gly-MCAD and Glu376Gly-MCAD. See the legend of Figure 2 for buffers. E376Q/E99G-MCAD $(10 \mu \mathrm{M})$ was reacted at $25^{\circ} \mathrm{C}$ with 10 equiv of $\mathrm{C}_{8} \mathrm{CoA}$ under aerobic conditions in $1.0 \mathrm{~mL}$ of Thunberg type optical cuvettes. E376G $(6.5 \mu \mathrm{M})$ was reacted with 7.7 equiv of $\mathrm{C}_{8} \mathrm{CoA}$ under anaerobic conditions $(0.2$ $\mu \mathrm{M}$ glucose oxidase and $10 \mathrm{mM}$ glucose). The solid- lines are the fits based on eq 3 . The dashed lines represent segments with a slope of 1 or 0 , where the intersection reflects ionization constants, and the construct is according to the Dixon rules (35).

Table 2: Kinetic Parameters for the Reduction of Glu376Gly- and Glu376Gln+Glu99Gly-MCAD with $\mathrm{C}_{8} \mathrm{CoA}$ and Comparison with Glu376Gln-MCAD ${ }^{a}$

\begin{tabular}{llll}
\hline & \multicolumn{1}{c}{ E376Q } & \multicolumn{1}{c}{ E376G } & E376Q+E99G \\
\hline$k_{\mathrm{r} 1}\left(\mathrm{~min}^{-1}\right)$ & $0.014 /(0.006)(\mathrm{pH} 7)$ & $0.5(\mathrm{pH} \leq 6)$ & $0.05(\mathrm{pH} \leq 6)$ \\
& $1.4 /(4.0)(\mathrm{pH} \mathrm{9.8)}$ & $0.05(\mathrm{pH} \geq 9)$ & $2(\mathrm{pH} \geq 9)$ \\
apparent $\mathrm{p} K$ & $-(>10)$ & $8.6,9.6$ & $7.4,9.0$ \\
$\quad$ values & & &
\end{tabular}

${ }^{a} k_{\mathrm{r} 1}$ is the rate of the first phase of enzyme flavin reduction at the indicated $\mathrm{pH}$ values and $25{ }^{\circ} \mathrm{C}$. For Glu376Gly- and Glu376GIn+Glu99Gly-MCAD, the values are those for the $\mathrm{pH}$ extremes of Figure 7. In the case of Glu376Gln-MCAD, the values are the experimental ones and those estimated from the plot of Figure 6 (italics in parentheses) at the indicated $\mathrm{pH}$ values.

Glu376Gln-MCAD and in the legend of Figure 7; they are listed in Table 2, and their magnitude is comparable to that for Glu376Gln-MCAD. However, the profiles of the dependences of $\log k_{\mathrm{r} 1}$ on $\mathrm{pH}$ that are depicted in Figure 7 are significantly different compared to those for Glu376GlnMCAD. With the Glu376Gln+Glu99Gly double mutant, the rate of the first phase, $k_{\mathrm{r}}$, is approximately 2 -fold faster, and it shows a clear indication of attaining a constant, $\mathrm{pH}-$ independent level above $\mathrm{pH} 9$ with a corresponding break. Further, while the rate of the Glu376Gln mutant decreases by approximately 4 orders of magnitude from $\mathrm{pH} 10$ to 6 , with the double mutant the decrease is only approximately 50 -fold in the same range, and at low $\mathrm{pH}$ there is again a clear indication for a second break that leads to a $\mathrm{pH}$ independent rate at $\mathrm{pH}<7$. In Dixon's terminology (35), the two breaks reflect apparent $\mathrm{p} K$ values of 7.4 and 9.0. Over the whole $\mathrm{pH}$ range, the rate of the double mutant is substantially greater than that of Glu376Gln-MCAD.

Most unexpectedly, the Glu376Gly-MCAD mutant shows an activity versus $\mathrm{pH}$ profile that has a substantially different course compared to that of Glu376Gln-MCAD and Glu376Gln+Glu99Gly-MCAD. First, its activity in the dehydrogenation reaction is approximately 2 orders of magnitude higher at $\mathrm{pH} 6-7$ compared to that of Glu376Gln- 


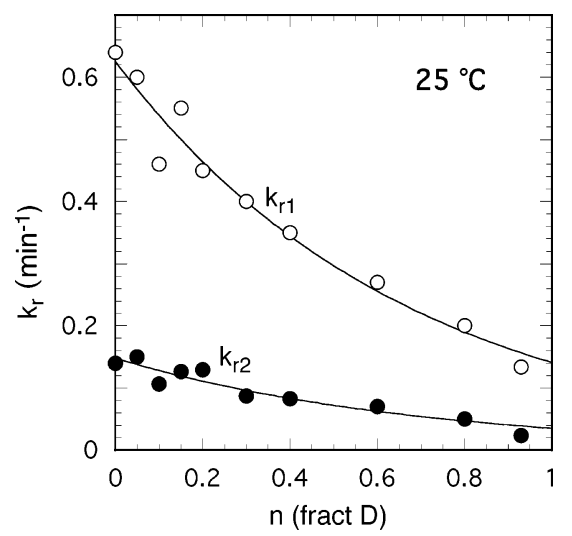

FIGURE 8: Proton inventories for the rates of the two phases of flavin reduction for Glu376Gln-MCAD at $25^{\circ} \mathrm{C}$. The experiments were conducted at $\mathrm{pL} 8.8$ and $25^{\circ} \mathrm{C} . k_{\mathrm{r} 1}$ and $k_{\mathrm{r} 2}$ are the rates obtained from the simulation of traces such as those in Figure 4 based on Scheme 2A and as described in the text (Supporting Information). The lines through the data points are the fits obtained using eq 4 . The observed KIE $\approx 4.5$.

MCAD. Second, this activity then decreases above $\mathrm{pH} 7.5$, reflecting an apparent $\mathrm{p} K$ of $\approx 8.6$ (Figure 7). The data points at $\mathrm{pH}>10$ are compatible with a second break with a $\mathrm{p} K$ around $\mathrm{pH}$ 9.5. At high $\mathrm{pH}$, the activity of this mutant is approximately $1 / 20$ of that of Glu376Gln-MCAD.

Proton Inventory of Glu376Gln-MCAD Reduction with the Substrate Octanoyl-CoA. On the basis of the hypothesis that dehydrogenation with the Glu376 mutants reflects the rate of spontaneous or $\mathrm{H}_{2} \mathrm{O} / \mathrm{HO}^{-}$-assisted dissociation of the substrate $\alpha \mathrm{C}-\mathrm{H}$, we have attempted to gather information about the mode of transfer of the resulting $\mathrm{H}^{+}$to solvent (or to solvent-borne acceptors). Proton inventories can yield useful information about such processes (52) and are obtained by measuring the dependence of kinetic rates from the fraction $n\left(=\left[\mathrm{H}_{2} \mathrm{O}\right] /\left[\mathrm{D}_{2} \mathrm{O}\right]\right)$, the atom fraction of deuterium in the solvent.

The data obtained with this procedure were then used to obtain the proton inventories depicted in Figures 8 and 9. It should be pointed out that during the course of measurements no exchange of $\mathrm{H}$ at positions $\alpha \mathrm{C}-\mathrm{H}$ or $\beta \mathrm{C}-\mathrm{H}$ occurs. This was verified by incubating $\mathrm{C}_{8} \mathrm{CoA}(40 \mathrm{mM})$ overnight in a NMR tube in the presence of Gln376Glu-MCAD $(0.5 \mu \mathrm{M})$ or in its absence at pD 7.6 and $25{ }^{\circ} \mathrm{C}$. During this measurement, no indication for relevant modifications such as exchange at the $\mathrm{C}_{8} \mathrm{CoA} \alpha$ - or $\beta$-positions or for hydrolysis was found. These conditions are similar to those employed earlier to study the rates of hydrogen exchange at these same positions by ${ }^{1} \mathrm{H}$ NMR in the presence of wtMCAD (5).

The data points in Figures 8 and 9B were fitted using eqs 4 (Figures 8 and 9B), 5 (Figure 9A), and 6 (Figure 9A) (52):

$$
\begin{gathered}
k_{n}=k_{\mathrm{o}} / Z^{n} \\
k_{n}=k_{\mathrm{o}}(1-n+\varphi n) / Z^{n} \\
k_{n}=k_{\mathrm{o}} /\left[(1-w)(1-n+\varphi n)+w Z^{n}\right]
\end{gathered}
$$

where $k_{n}$ values are the experimental data points at a fraction $n$ of $\mathrm{D}_{2} \mathrm{O}, k_{\mathrm{o}}$ is the rate constant at $0 \% \mathrm{D}_{2} \mathrm{O}, Z$ is the medium isotope effect, $\varphi$ is the fractionation factor (inverse IE) for a single site, and $w$ is a factor giving the fractional extent to which a reaction step limits the rate as described in ref 52 .

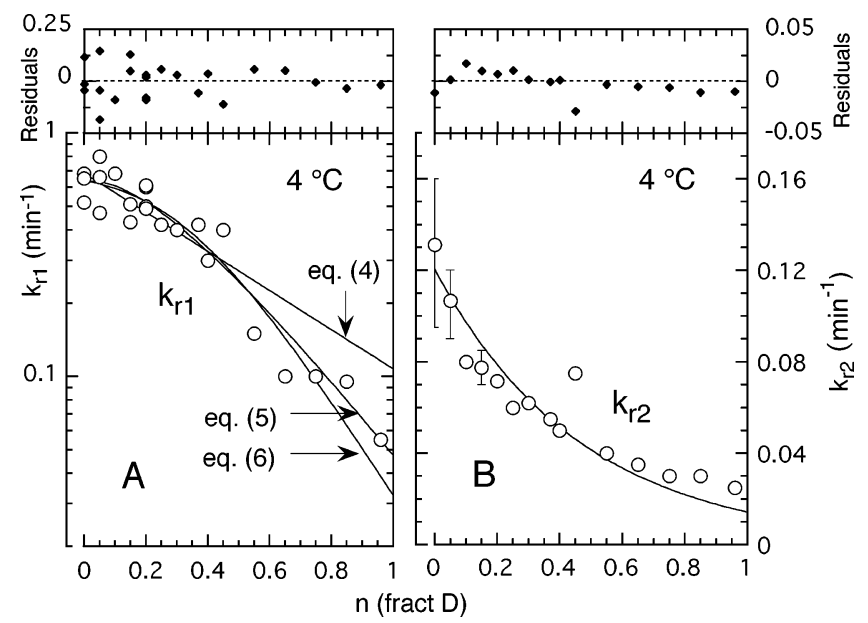

FIGURE 9: Proton inventories for the rates of the two phases of flavin reduction for Glu376Gln-MCAD at $4{ }^{\circ} \mathrm{C}$. The experiments were carried out at $\mathrm{pL}$ 9.25-9.3, and analysis of the original traces (see Figure 4) was carried out via simulations as detailed in the text (Supporting Information). (A) Dependence of $k_{\mathrm{r} 1}$ on $n$. The curves through the data points are the fits obtained on the basis of the indicated equations. The observed SKIE $\left(k_{n=0} / k_{n=0} 96\right)$ is $\approx 12$. (B) Plot of $k_{\mathrm{r} 2}$ and fit based on eq 4 . The vertical bars denote the scatter of the data ( $n=0$, four measurements; $n=0.05$ and 0.15 , three measurements; remainder, single measurements). The observed SKIE $\approx 5.5$. The top panels show the residuals. Note the different scales on the ordinates of panels A $(\log )$ and B (linear).

Table 3: Parameters Obtained from the Analysis of Proton Inventories Such as Those Shown in Figures 8 and 9 Based on the Equations Given There ${ }^{a}$

\begin{tabular}{lccccc}
\hline & \multicolumn{2}{c}{$k_{\mathrm{r} 1}$} & & \multicolumn{2}{c}{$k_{\mathrm{r} 2}$} \\
\cline { 2 - 3 } \cline { 5 - 6 } & $4{ }^{\circ} \mathrm{C}, \mathrm{pH}$ & $25^{\circ} \mathrm{C}, \mathrm{pH}$ & & $4^{\circ} \mathrm{C}, \mathrm{pH}$ & $25^{\circ} \mathrm{C}, \mathrm{pH}$ \\
& 9.3, eq 6 & 8.8, eq 4 & & 9.3, eq 4 & 8.8, eq 4 \\
\hline$\varphi$ & 0.5 & - & & - & - \\
$Z$ & 96 & 4.4 & & 4.5 & 3.1 \\
$k_{\mathrm{o}}\left(\mathrm{min}^{-1}\right)$ & 0.64 & 0.63 & & 0.1 & 0.15 \\
\hline
\end{tabular}

${ }^{a} \varphi$ is the fractionation factor (inverse IE). $Z$ is the medium isotope effect. $k_{\mathrm{o}}$ is the rate constant at $0 \% \mathrm{D}_{2} \mathrm{O}$. See the legends of Figures 8 and 9 and the text for details.

The various parameters obtained from these procedures are listed in Table 3.

\section{DISCUSSION}

Comment on the Kinetic System and on the Method of Evaluation of Rate Constants. In a previous paper (7), dealing with the kinetics of MCAD studied by rapid reaction techniques, we have pointed out the problems inherent to the evaluation of systems containing reversible steps in which different rate constants are on the same order of magnitude. This topic has recently been treated theoretically by Fisher et al. $(48,49)$ and Palfey and Fagan $(50)$. These authors have pointed out that values for rate constants obtained from such systems can vary widely in their magnitude and differ considerably from the intrinsic constants since they result from equations that do not have unique solutions. For this reason, we have resorted to simulation procedures as described in the Supporting Information that appear to yield better results when information is available about the spectral properties of involved species and when only the core kinetic steps, $k_{\mathrm{r} 1} / k_{\mathrm{r}-1}$ and $k_{\mathrm{r} 2}$, are treated as variables. The results thus concur with the results of a previous analysis (7) and 
with the theoretical treatments by Fisher et al. $(48,49)$ and Palfey and Fagan (50). These predict that in the case of kinetic systems involving several (reversible) steps that are not sufficiently separated analysis based on exponential fitting will not produce reliable data.

Interpretation of Solvent KIEs and of Proton Inventory Studies. Of the $k_{\mathrm{r} 1(n)}(n)$ dependences of rate constant $k_{\mathrm{r} 1}$ on the atom fraction of deuterium $(n)$ in the aqueous solvent, the most dramatic is that for the rate constant $k_{\mathrm{r} 1(n)}(n)$ shown in Figure 9A. For this case, the rate constants at low $n$ remain fairly constant to around $n=0.2$ and then drop sufficiently for an overall solvent isotope effect for a $k_{\mathrm{r} 1(0)} / k_{\mathrm{r} 1(1)}$ of $12-$ 18 to be produced. A limited number of qualitatively different models can be expected to reproduce this kind of curve. We have been able to produce quantitative or semiquantitative agreement with the experimental data for two kinds of models: (a) a one-step model combining a normal isotope effect from multiple sites with an inverse isotope effect from one site and (b) a two-step model in which one step generates a multisite normal isotope effect and a second step an inverse isotope effect from nucleophilic or general base participation by hydroxide ion. The two models are not equally attractive from a quantitative viewpoint.

(a) One-Step Model. A one-step model will have the general form

$$
k_{n}=k_{\mathrm{o}} \times \mathrm{TSC}(n) / \operatorname{RSC}(n)
$$

where TSC and RSC mean "transition-state contribution" and "reactant-state contribution", respectively. If $\operatorname{TSC}(n)=1-$ $n+n \varphi$ and $\operatorname{RSC}(n)=Z^{n}$, the data can be fitted on the basis of eq 5 with a $\varphi$ of 6 and a $Z$ of 80 (Figure 9A, eq 5). This corresponds to a physical model with two characteristics. First, there is an event such as an enzyme conformational change that produces a net loosening of the binding potential at a large number of hydrogenic sites in the structure of the protein and associated waters of solvation, as the reactant state is converted to the transition state. The overall result is a normal isotope effect of 80 , arising from a very large number of sites. Second, a single site becomes more tightly bound as the reactant state is converted to the transition state such that its isotopic fractionation factor $\varphi$ changes from 1.0 in the reactant state to 6 in the transition state. While large multisite isotope effects have been noted for some protein structural phenomena previously $(53,54)$, the singlesite transition-state fractionation factor of 6 is much more difficult to accept. While fractionation at individual protein sites has been found in some NMR studies to generate values larger than unity, values of around 1.4-1.5 are essentially the observed upper limit (55-57); reliable values this large would require a potential so stiff around the isotopic center as to seem prima facie unphysical.

(b) Two-Step Model. The expected form of $k_{n}$ for a twostep reaction can be obtained as follows (an example is given in ref 53). The steady-state rate constant $k_{n}$ for a sequence of two reactions with rate constants $k_{\mathrm{a} n}$ and $k_{\mathrm{b} n}$ is given by

$$
\left(k_{n}\right)^{-1}=\left(k_{\mathrm{a} n}\right)^{-1}+\left(k_{\mathrm{b} n}\right)^{-1}
$$

whence multiplication by $k_{0}$ (rate constant at $n=0$ ) yields

$$
k_{0}\left(k_{n}\right)^{-1}=\left(k_{0} / k_{\mathrm{a} 0}\right)\left(k_{\mathrm{a} n} / k_{\mathrm{a} 0}\right)^{-1}+\left(k_{0} / k_{\mathrm{b} 0}\right)\left(k_{\mathrm{b} n} / k_{\mathrm{b} 0}\right)^{-1}
$$

Note that $\left(k_{0} / k_{\mathrm{a} 0}\right)+\left(k_{0} / k_{\mathrm{b} 0}\right)=1$ and that $k_{0} / k_{\mathrm{a} 0}$ and $k_{0} / k_{\mathrm{b} 0}$ are weighting factors that define the fractional degree to which the $k_{\mathrm{a}}$ step and the $k_{\mathrm{b}}$ step, respectively, determine the rate for $n=0$. We can replace $k_{0} / k_{\mathrm{a} 0}$ with $w_{\mathrm{a}}$ and $k_{0} / k_{\mathrm{b} 0}$ with $1-w_{\mathrm{a}}$. Furthermore, $\left(k_{\mathrm{a} n} / k_{\mathrm{a} 0}\right)^{-1}=\mathrm{RSCa}(n) / \mathrm{TSCa}(n)$, and $\left(k_{\mathrm{b} n} / k_{\mathrm{b} 0}\right)^{-1}=\operatorname{RSCb}(n) / \operatorname{TSCb}(n)$. Taking $\operatorname{RSCa}(n)$ to be $1-n+n(0.5), \operatorname{TSCa}(n)$ to be $1, \operatorname{RSCb}(n)$ to be $90^{n}$, and $\operatorname{TSCb}(n)$ to be 1 , we obtain

$$
k_{0}\left(k_{n}\right)^{-1}=\left(1-w_{\mathrm{a}}\right)[1-n+n(0.5)]+w_{\mathrm{a}}(90)^{n}
$$

A $w_{\mathrm{a}}$ value of 0.2 then produces a line that is close to that for the one-step model (Figure 9A, trace for eq 6). This model would correspond to a situation in which two steps in succession (we cannot deduce the order of the steps in series) occur and their steady-state combination then generates $k_{\mathrm{r}}$. The step with $k_{\mathrm{a}}$ as a rate constant is around $80 \%$ rate-limiting in $\mathrm{H}_{2} \mathrm{O}$ and corresponds to a mechanism in which the reactant state has an enzyme-bound hydroxide ion $(\varphi=0.5)$ which then becomes bound to a proton being abstracted from substrate in the transition state so that $\varphi=$ 1 in the transition state. The step with $k_{\mathrm{b}}$ as a rate constant is around $20 \%$ rate-limiting in $\mathrm{H}_{2} \mathrm{O}$ and generates a multisite isotope effect of 90-100, probably arising from small changes in binding at very many backbone $\mathrm{NH}(\mathrm{D})$ sites, most simply in a protein conformational change.

In principle, the results can be described equally well on the basis of the one-step model and the two-step model. However, the one-step model requires the assignment to the transition state of an unprecedented fractionation factor of $\sim 6$, suggesting the presence of an exchangeable hydrogen in a very steep potential well. The two-step model, in contrast, requires in one step an enzyme-bound hydroxide ion with the normally observed fractionation factor, an idea that is supported by the $\mathrm{pH}$ dependence (Figure 6), and in a second step a conformation change or similar event that produces a large normal isotope effect presumably arising from many small isotope effects at backbone hydrogenic sites, which has been observed in other enzymatic reactions. Thus, on the grounds of plausibility, the two-step model appears to be preferable.

There are also relevant differences in the profiles for the inventories at $4{ }^{\circ} \mathrm{C}$ compared to those at $25^{\circ} \mathrm{C}$ (Figures 8 and 9A). The dependencies of $k_{\mathrm{r} 1}$ and $k_{\mathrm{r} 2}$ at $25^{\circ} \mathrm{C}$ and of $k_{\mathrm{r} 2}$ at $4{ }^{\circ} \mathrm{C}$ exhibit similar bowl-shaped profiles that reflect a dependence on $Z^{n}(52,53)$; i.e., they probably reflect steps related to conformational changes. This contrasts with the just discussed case of $k_{\mathrm{r} 1}$ at $4{ }^{\circ} \mathrm{C}$ that is assumed to reflect two processes. A possible interpretation of this difference is that the $\mathrm{H}^{+}$removal step becomes more rapid with temperature (steeper temperature dependence) relative to conformational changes. The latter appear to be dominant for $k_{\mathrm{r} 2}$ at $4{ }^{\circ} \mathrm{C}$ and become completely rate-limiting at $25{ }^{\circ} \mathrm{C}$ also for $k_{\mathrm{r} 1}$.

Mechanism of Substrate Binding and Dehydrogenation. Binding of $\mathrm{C}_{8} \mathrm{CoA}$, the best substrate of MCAD, is compatible with the minimal two-step process depicted in Scheme 2 ( $K_{\mathrm{b}}$ binding steps). However, further steps that do not manifest spectral effects cannot be excluded.

It should be kept in mind that binding of the large CoA substrates will encounter major steric constraints. The active site cavity in which the fatty acid tail is bound is a narrow 
Scheme 3: Representation of the Processes Thought To Occur at the Active Center of MCAD Mutants during Substrate Dehydrogenation $^{a}$
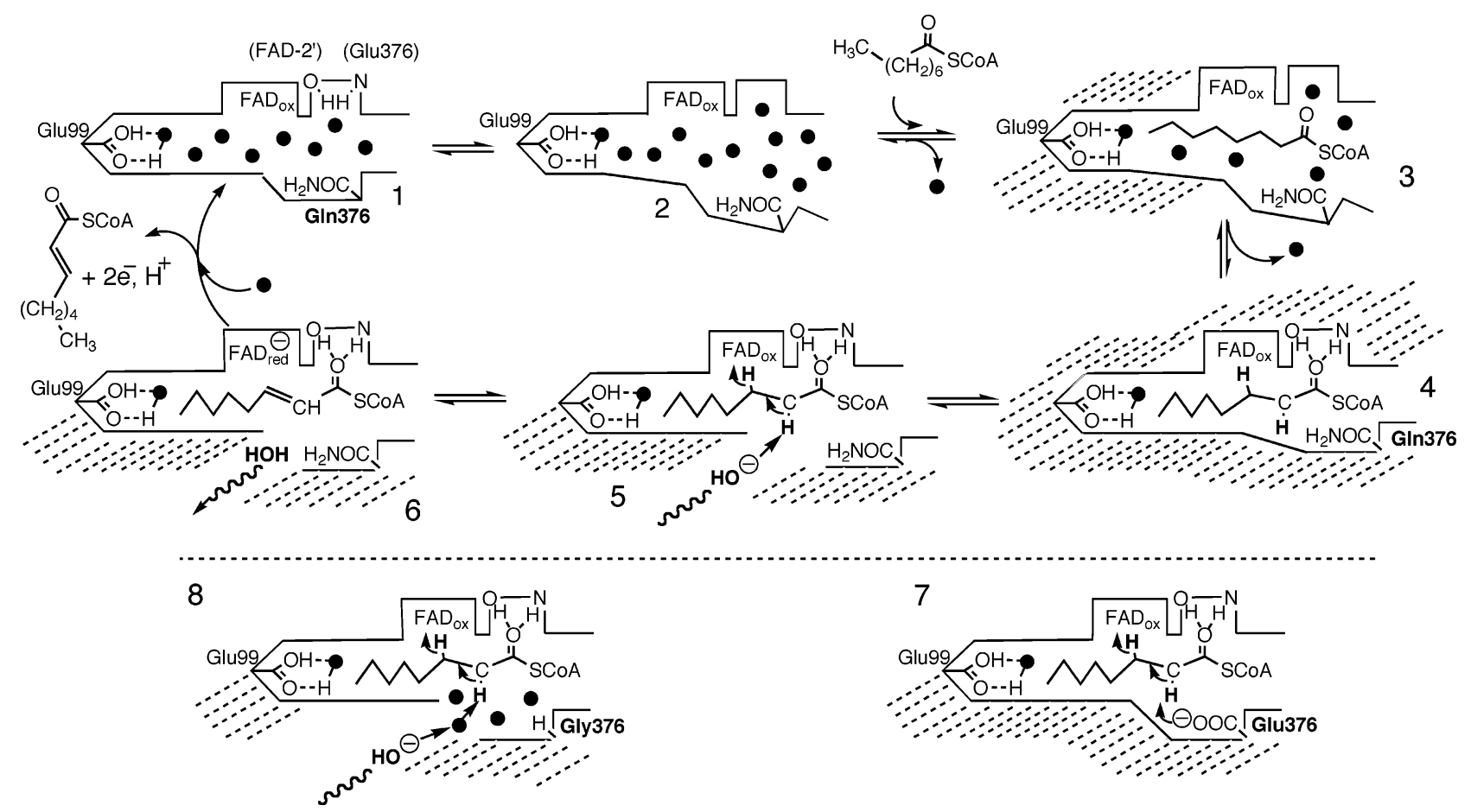

${ }^{a}$ Dots (๑) represent $\mathrm{H}_{2} \mathrm{O}$ molecules; shaded areas indicate regions of restricted access (shown only in selected diagrams for clarity). 1 represents the active site of empty MCAD adapted from the three-dimensional structure of the uncomplexed enzyme in which Glu376 has been substituted for Gln376. It contains eight $\mathrm{H}_{2} \mathrm{O}$ molecules linked by H-bonds. $\mathbf{2}$ is an open form into which substrate enters to form $\mathbf{3}$, a primary encounter complex, $\mathrm{E}_{\mathrm{ox}}-\mathrm{S}$ (compare to Scheme 2). In a subsequent step, the substrate thioester carbonyl docks into an "oxycarbanion hole" that is flanked by a 2'-OH group from the FAD-ribityl side chain and the backbone $\mathrm{NH}$ group from residue 376 . This triggers the expulsion of all but the one $\mathrm{H}_{2} \mathrm{O}$ molecule linked to Glu99 at the bottom of the cavity (51). This process is reflected by the transition to a more hydrophobic environment as reflected by the resolution of the flavin spectra (see Figure 1) and forms species 4 (probably equivalent to $\mathrm{E}_{\mathrm{ox}}-\mathrm{S}$ in Scheme 2). 4-6 are characterized as being shielded from solvent and having a restricted accessibility to oxygen. For access of solvent-borne $\mathrm{HO}^{-}$and its reaction with the substrate $\alpha \mathrm{C}-\mathrm{H}(\mathbf{5})$, the active site, or some of its domains, must open up, this requiring the rupture of several H-bonds. Flavin reduction $(\mathbf{5} \rightarrow \mathbf{6})$ leads to formation of the product complex (6) that might be stabilized by the expulsion of water. $\mathbf{7}$ is the representation analogous to 4 for the $\mathrm{E}_{\mathrm{ox}}-\mathrm{S}$ complex of wtMCAD (51). In this case, the trapped negative charge of the Glu-COO ${ }^{-}$species relaxes by transfer onto the flavin to form a complex analogous to $\mathbf{6}$. In the case of the Glu376Gly mutant 8, the space occupied by Glu376 in wtMCAD is likely to be taken up by three or four $\mathrm{H}_{2} \mathrm{O}$ molecules. These might facilitate attack of solvent-borne $\mathrm{HO}^{-}$or the transfer of $\mathrm{H}^{+}$to bulk solvent, leading to an increased rate of dehydrogenation.

tube containing, in the uncomplexed state, eight $\mathrm{H}_{2} \mathrm{O}$ molecules in a linear arrangement held together by $\mathrm{H}$-bonds (51). When $\mathrm{C}_{8} \mathrm{CoA}$ binds, seven of these eight $\mathrm{H}_{2} \mathrm{O}$ molecules are expelled (51). Binding of substrate is thus likely to require extensive movements and/or rearrangements of protein domains around the active center, a process most likely to be affected by the presence of several H-bonds within the protein scaffold, the rupture of which could be concerted. By analogy, a similar process could be envisaged for the access of solvent-borne molecules such as $\mathrm{HO}^{-}$ (Scheme 3), and this would be at the origin of the observed, substantial KIEs for reactions that are assumed to be catalyzed by hydroxide.

The interpretation of the steps subsequent to binding, i.e., of substrate dehydrogenation, is even more complex, and for its discussion, a few mechanistic key points should be recalled. The active center of MCAD has the capacity to lower the microscopic $\mathrm{p} K_{\mathrm{a}}$ of a bound ligand $\alpha \mathrm{C}-\mathrm{H}$ by some 10-13 units compared to that of the free state $(10,23)$. In the case of $\mathrm{C}_{8} \mathrm{CoA}$, this $\mathrm{p} K$ would be around 8 . With wtMCAD, the abstracted $\mathrm{H}^{+}$will be ligated by the Glu376$\mathrm{COO}^{-}$active center base, this occurring concertedly with transfer of the $\beta \mathrm{C}-\mathrm{H}$ to the flavin as a hydride (2). With the Glu376Gln mutant, however, the putative $\mathrm{H}^{+}$generated as shown in Scheme 3 also requires binding to a base. An inspection of the three-dimensional structure around the active site shows the presence of glutamate 99 at its bottom. While this would be a logical candidate, its role as a base is excluded since the Glu376Gln+Glu99Gly-MCAD double mutant exhibits an activity profile similar to that of Glu376GlnMCAD (Figure 6). The changes in slope shown in Figure 7 are not to be attributed to specific groups at the active center for the simple reason that there are none that can account for them (51). It is thus likely that these apparent $\mathrm{p} K$ values correspond to changes in mechanisms or that they reflect $\mathrm{p} K$ values of groups outside the active site that govern specific movements of protein domains or affect access of solvent or transport of $\mathrm{H}^{+}$.

The profiles of Figure 7 show a linear increase of $\log k_{\mathrm{r} 1}$ with $\mathrm{HO}^{-}$concentration. This leads to the conclusion that in the case of Glu376Gln-MCAD abstraction of $\mathrm{H}^{+}$from $\alpha \mathrm{C}-\mathrm{H}$ is directly promoted either by solvent-borne $\mathrm{HO}^{-}$or by $\mathrm{H}_{2} \mathrm{O}$ linked to $\mathrm{HO}^{-}$. The corresponding rate equation would be

$$
k_{\mathrm{obs}}=k\left[\mathrm{E}_{\mathrm{ox}}-\mathrm{S}\right]\left[\mathrm{HO}^{-}\right]
$$

The sister $\mathrm{pH}$ profile for Glu376Gly-MCAD (Figure 7) is an apparent puzzle since, by intuition, one would expect a similar mechanism and consequently a similar $\mathrm{HO}^{-}$con- 
centration dependence. However, it should be noted that the two profiles in Figure 7 are crude mirror images (on the ordinate), and a simple interpretation would be that opposite shifts of the underlying apparent $\mathrm{p} K$ values lead to their crossover. Indeed, this would agree with Dixon's rules that demand that the bends reflected by the two types of profiles (upward vs downward) reflect the same type of ionization (of complexed vs free species) (35); the apparent $\mathrm{p} K$ values would thus have the same origin. Attribution of these apparent $\mathrm{p} K$ values to specific microscopic ionizations or to changes in mechanism is not possible on the basis of the data presented here. Intriguing is also the observation that at $\mathrm{pH}$ 6-7 the activity of the Glu376Gly mutant is $1-2$ orders of magnitude higher compared to that of Glu376GlnMCAD. A possible clue arises from inspection of the active site of MCAD. The space occupancy of the Gln side chain can be assumed to correspond to that of three or four $\mathrm{H}_{2} \mathrm{O}$ molecules which would be present in the Glu376Gly mutant. In the latter, the space around the substrate $\alpha \mathrm{C}-\mathrm{H}$ position would thus be more hydrophilic, weaken the forces that keep the active site tight, and thus promote $\mathrm{H}^{+}$abstraction/ neutralization and/or access of solvent-borne species such as oxygen.

Conclusions. As also pointed out elsewhere (2), MCAD appears to seal itself off from the environment during catalysis, the reasons for this being the necessities of the chemistry of the enzyme for both the dehydrogenation step and the prevention of the reaction of the reduced enzyme with dioxygen $(2,3)$. This shielding of the active site appears to be extremely effective, and access of solvent-borne molecules such as $\mathrm{HO}^{-}$appears to require the concomitant rupture of a series of $\mathrm{H}$-bonds such as in a rearrangement of a protein domain. As discussed recently in detail by Palfey and Fagan (50) in the case of a concerted process, the observed effect would be the product of singular KIEs, and this, in turn, would result in the observed large medium KIEs. In a general sense, the observation of such large SKIEs is in accordance with the presence of very rigid frames around the active site and with the concept that movements involve large domains and sections of the protein.

The cavity close to the flavin and inside MCAD contains eight $\mathrm{H}_{2} \mathrm{O}$ molecules in the absence of ligands, while a single one of these is found in the reduced enzyme-octenoyl (=product) complex (51). The number of $\mathrm{H}_{2} \mathrm{O}$ molecules present is likely to vary depending on the size of the substrate [MCAD accepts $\mathrm{C}_{4}$ to $\mathrm{C}_{16} \mathrm{CoA}$ substrates (2)]. It is thus conceivable that some of the bound water molecules become fixed among the active sites upon substrate binding. As a result, the enzyme-substrate complex (4 in Scheme 3 and $\mathrm{E}_{\mathrm{ox}}-\mathrm{S}$ in Scheme 2) might be heterologous with respect to its $\mathrm{H}_{2} \mathrm{O}$ content. Thus, there would be more than one structure that tends to be trapped in fractions of the total. This could lead to different forms of reactants $\left(\mathrm{E}_{\mathrm{ox}}-\mathrm{S} \cdot n \mathrm{H}_{2} \mathrm{O}\right)$ where water networks may modulate the reactivity of the complex and in particular affect medium effects in proton inventories. This could generate several exponential terms, each with its characteristic rate constant that would correspond to the different phases of enzyme reduction (corresponding to $k_{\mathrm{r} 1}$ and $k_{\mathrm{r} 2}$ in Scheme 2). In agreement with this concept is the observation that with some substrates (59) and in particular with $\mathrm{C}_{14} \mathrm{CoA}$, a substrate with a large tail, dehydrogenation by MCAD is monophasic (R. Gradinaru and S. Ghisla, unpublished observation). Substrates with a small tail such as butyryl-CoA lead to dehydrogenation involving two or more phases $(6,7)$. This suggests that factors related to the size of the substrate acyl moiety can affect the rates and ratio of the phases. The deviant behavior of the Glu376GlyMCAD mutant (Figure 7) can be rationalized analogously. The presence of some additional $\mathrm{H}_{2} \mathrm{O}$ molecules that replace the Glu side chain modifies the fine-tuning of the dehydrogenation reaction in an unexpected way to produce the effects depicted in Figure 7.

Since for Glu376Gln- and Glu376Gly-MCAD mutants proton transfers that accompany dehydrogenation must be occurring along water chains, the large solvent isotope effects and complicated proton inventories become easier to understand. Thus, the observed solvent isotope effects could originate in overall conformational changes, formation and adjustment of fixed water networks, transfer of protons along these networks, uptake of hydroxide ion or equivalent release of a proton before reaction, all of the above, or many in combination.

\section{ACKNOWLEDGMENT}

We thank Mr. Volker Kieweg and Dr. Stefan Engst for carrying out some of the preliminary experiments and Mrs. S. Feindler-Boeck for skillful technical assistance.

\section{SUPPORTING INFORMATION AVAILABLE}

Methods and criteria used for carrying out the fitting and simulation of kinetic processes. This material is available free of charge via the Internet at http://pubs.acs.org.

\section{REFERENCES}

1. Engel, P. C. (1992) Acyl-CoA Dehydrogenases, in Chemistry and Biochemistry of Flavoenzymes (Müller, F., Ed.) pp 597-655, CRC Press, Boca Raton, FL.

2. Ghisla, S., and Thorpe, C. (2004) Acyl-CoA dehydrogenases. A mechanistic overview, Eur. J. Biochem. 271, 494-508.

3. Kim, J. J., and Miura, R. (2004) Acyl-CoA dehydrogenases and acyl-CoA oxidases. Structural basis for mechanistic similarities and differences, Eur. J. Biochem. 271, 483-493.

4. Ikeda, Y., Hine, D. G., Okamura-Ikeda, K., and Tanaka, K. (1985) Mechanism of action of short-chain, medium-chain, and longchain acyl-CoA dehydrogenases. Direct evidence for carbanion formation as an intermediate step using enzyme-catalyzed C-2 proton/deuteron exchange in the absence of C-3 exchange, J. Biol. Chem. 260, 1326-1337.

5. Ghisla, S., Thorpe, C., and Massey, V. (1984) Mechanistic studies with general acyl-CoA dehydrogenase and butyryl-CoA dehydrogenase: Evidence for the transfer of the $\beta$-hydrogen to the flavin N(5)-position as a hydride, Biochemistry 23, 3154-3160.

6. Pohl, B., Raichle, T., and Ghisla, S. (1986) Studies on the reaction mechanism of general acyl-CoA dehydrogenase. Determination of selective isotope effects in the dehydrogenation of butyrylCoA, Eur. J. Biochem. 160, 109-115.

7. Schopfer, L. M., Massey, V., Ghisla, S., and Thorpe, C. (1988) Oxidation-reduction of general acyl-CoA dehydrogenase by the butyryl-CoA/crotonyl-CoA couple. A new investigation of the rapid reaction kinetics, Biochemistry 27, 6599-6611.

8. Hazekawa, I., Nishina, Y., Sato, K., Shichiri, M., and Shiga, K. (1995) Substrate activating mechanism of short-chain acyl-CoA, medium-chain acyl-CoA, long-chain acyl-CoA, and isovalerylCoA dehydrogenases from bovine liver: A resonance Raman study on the 3-ketoacyl-CoA complexes, J. Biochem. 118, 900910 .

9. Engst, S., Vock, P., Wang, M., Kim, J. J., and Ghisla, S. (1999) Mechanism of activation of acyl-CoA substrates by medium chain acyl-CoA dehydrogenase: interaction of the thioester carbonyl with the flavin adenine dinucleotide ribityl side chain, Biochemistry 38, 257-267. 
10. Vock, P., Engst, S., Eder, M., and Ghisla, S. (1998) Substrate activation by acyl-CoA dehydrogenases: Transition-state stabilization and $\mathrm{pK}$ 's of involved functional groups, Biochemistry 37, $1848-1860$.

11. Nishina, Y., Sato, K., Tamaoki, H., Tanaka, T., Setoyama, C., Miura, R., and Shiga, K. (2003) Molecular mechanism of the drop in the pKa of a substrate analog bound to medium-chain acylCoA dehydrogenase: Implications for substrate activation, $J$. Biochem. 134, 835-842.

12. Gradinaru, R., Dmitrenko, O., Narayana, K. L., Bach, R., and Ghisla, S. (2005) Role of the active center Thr168-flavinN(5) H-bond in MCAD catalysis, in Flavins and Flavoproteins 2005, Proceedings of the 15th International Symposium (Nishino, T., Miura, R., Tanokura, M. and Fukui, K., Eds.) pp 205-210, ARchiTect Inc., Tokyo, Japan.

13. Powell, P. J., and Thorpe, C. (1988) 2-Octynoyl coenzyme A is a mechanism-based inhibitor of pig kidney medium-chain acyl coenzyme A dehydrogenase: Isolation of the target peptide, Biochemistry 27, 8022-8028.

14. Bross, P., Engst, S., Strauss, A. W., Kelly, D. P., Rasched, I., and Ghisla, S. (1990) Characterization of wild-type and an active site mutant of human medium chain acyl-CoA dehydrogenase after expression in Escherichia coli, J. Biol. Chem. 265, 7116-7119.

15. Engst, S. (1993) Ph.D. Thesis, Universität Konstanz, Konstanz, Germany.

16. Djordjevic, S., Dong, Y., Paschke, R., Frerman, F. E., Strauss, A. W., and Kim, J.-J. P. (1994) Identification of the catalytic base in long chain acyl-CoA dehydrogenase, Biochemistry 33, 42584264.

17. Nandy, A., Kieweg, V., Kräutle, F. G., Vock, P., Küchler, B., Bross, P., Kim, J. J., Rasched, I., and Ghisla, S. (1996) Mediumlong-chain chimeric human Acyl-CoA dehydrogenase: Mediumchain enzyme with the active center base arrangement of longchain Acyl-CoA dehydrogenase, Biochemistry 35, 12402-12411.

18. Lee, H. J., Wang, M., Paschke, R., Nandy, A., Ghisla, S., and Kim, J. J. (1996) Crystal structures of the wild type and the Glu376Gly/Thr255Glu mutant of human medium-chain acyl-CoA dehydrogenase: Influence of the location of the catalytic base on substrate specificity, Biochemistry 35, 12412-12420.

19. Gopalan, K. V., and Srivastava, D. K. (2002) Beyond the Proton Abstracting Role of Glu-376 in Medium-Chain Acyl-CoA Dehydrogenase: Influence of Glu-376 $\rightarrow$ Gln Substitution on Ligand Binding and Catalysis, Biochemistry 41, 4638-4648.

20. Ankele, K., Melde, K., Engst, S., Bross, P., Ghisla, S., and Strauss, A. W. (1991) On the Role of Glu ${ }^{376}$ in Catalysis of Acyl-CoA Dehydrogenases, in Flavins and Flavoproteins 1990, Proceedings of the 10th International Symposium (Curti, B., Ronchi, S., and Zanetti, G., Eds.) pp 325-328, W. de Gruyter, Berlin.

21. Engst, S., Bross, P., Stiemke, J., Schieber, A., Strauss, A. W., Kelly, D. P., Rasched, I., and Ghisla, S. (1991) Some Properties of Glu-376-Gln Active Site Mutant of Human Medium-Chain Acyl-CoA Dehydrogenase, in Flavins and Flavoproteins, Proceedings of the 10th International Symposium (Curti, B., Ronchi, S., and Zanetti, G., Eds.) pp 319-324, W. de Gruyter, Berlin.

22. Gradinaru, R. V., Kieweg, V., Küchler, B., and Ghisla, S. (2002) On the Role of the 376-Functional Group in Catalysis by Medium Chain Acyl-CoA-dehydrogenase, in Flavins and Flavoproteins 2002 Proceedings of the 14th International Symposium (Chapman, S., Perham, R., and Scrutton, N., Eds.) pp 193-198, Agency for Scientific Publication, Berlin.

23. Rudik, I., Ghisla, S., and Thorpe, C. (1998) Protonic equilibria in the reductive half-reaction of the medium-chain acyl-CoA dehydrogenase, Biochemistry 37, 8437-8445.

24. DuPlessis, E. R., Pellett, J., Stankovich, M. T., and Thorpe, C. (1998) Oxidase activity of the acyl-CoA dehydrogenases, Biochemistry 37, 10469-10477.

25. Langkau, B. (1993) Ph.D. Thesis, University of Konstanz, Konstanz, Germany.

26. Macheroux, P., Seth, O., Bollschweiler, C., Schwarz, M., Kurfürst, M., Au, L. C., and Ghisla, S. (2001) L-Amino-acid oxidase from the Malayan pit viper Calloselasma rhodostoma. Comparative sequence analysis and characterization of active and inactive forms of the enzyme, Eur. J. Biochem. 268, 1679-1686.

27. Lehmann, T. C., and Thorpe, C. (1990) Alternate Electron Acceptors for Medium-Chain Acyl-CoA Dehydrogenase: Use of Ferricenium Salts, Biochemistry 29, 10594-10602.

28. Nandy, A., Bross, P., Kräutle, F., Rasched, I., and Ghisla, S. (1994) Long-chain Specific Enzyme from Medium-chain Acyl-CoA Dehydrogenase, in Flavins and Flavoproteins 1993; Proceedings of the Eleventh International Symposium, Nagoya (Yagi, K., Ed.) pp 327-330, W. de Gruyter, Berlin.

29. Williamson, G., Engel, P. C., Mizzer, J. P., Thorpe, C., and Massey, V. (1982) Evidence That the Greening Ligand in Native Butyryl-CoA Dehydrogenase Is a CoA Persulfide, J. Biol. Chem. 257, 4314-4320.

30. Al-Arif, A., and Blecher, M. (1969) Synthesis of fatty acyl CoA and other thio esters using N-hydroxysuccinimide esters of fatty acids, J. Lipid Res. 10, 344-345.

31. Decker, K. (1959) Die aktivierte Essigsäure - Das Coenzym A und seine Acylderivate im Stoffwechsel der Zelle, Vol. 57, Ferdinand Enke Verlag, Stuttgart, Germany.

32. Whitby, L. G. (1953) A New Method for Preparing Flavin-adenine Dinucleotide, Biochem. J. 54, 437-442.

33. Gampp, H., Maeder, M., Meyer, C. J., and Zuberbühler, A. D. (1985) Calculation of Equilibrium Constants from Multiwavelength Spectroscopic Data. I. Mathematical Considerations, Talanta 32, 95-101.

34. Strickland, S., Palmer, G., and Massey, V. (1975) Determination of Dissociation Constants and Specific Rate Constants of EnzymeSubstrate (or Protein-Ligand) Interactions from Rapid Reaction Kinetic Data, J. Biol. Chem. 250, 4048-4052.

35. Dixon, M., and Webb, E. C. (1979) Enzymes, Longman/Academic Press, New York.

36. Srivastava, D. K., Wang, S., and Peterson, K. L. (1997) Isothermal titration microcalorimetric studies for the binding of octenoylCoA to medium chain acyl-CoA dehydrogenase, Biochemistry 36 , 6359-6366.

37. Beckmann, J. D., and Frerman, F. E. (1983) The effects of pH, ionic strength, and chemical modifications on the reaction of electron transfer flavoprotein with an acyl coenzyme A dehydrogenase, J. Biol. Chem. 258, 7563-7569.

38. Kieweg, V., Kräutle, F. G., Nandy, A., Engst, S., Vock, P., AbdelGhany, A. G., Bross, P., Gregersen, N., Rasched, I., Strauss, A. and Ghisla, S. (1997) Biochemical characterization of purified, human recombinant Lys304 $\rightarrow$ Glu medium-chain acyl-CoA dehydrogenase containing the common disease-causing mutation and comparison with the normal enzyme, Eur. J. Biochem. 246, 548556.

39. Powell, P. J., Lau, S. M., Killian, D., and Thorpe, C. (1987) Interaction of acyl coenzyme A substrates and analogues with pig kidney medium-chain acyl-CoA dehydrogenase, Biochemistry 26, 3704-3710.

40. Lau, S. M., Brantley, R. K., and Thorpe, C. (1988) The reductive half-reaction in acyl-CoA dehydrogenase from pig kidney: Studies with thiaoctanoyl-CoA and oxaoctanoyl-CoA analogues, Biochemistry 27, 5089-5095.

41. Wang, R., and Thorpe, C. (1991) The reductive half-reaction in acyl-CoA oxidase from Candida tropicalis: Interaction with acylCoA analogues and an unusual thioesterase activity, Arch. Biochem. Biophys. 286, 504-510.

42. Müller, F., Mayhew, S. G., and Massey, V. (1973) On the effect of temperature on the absorption spectra of free and protein-bound flavins, Biochemistry 12, 4654-4662.

43. Thorpe, C., Matthews, R. G., and Williams, C. H., Jr. (1979) Acylcoenzyme A dehydrogenase from pig kidney. Purification and properties, Biochemistry 18, 331-337.

44. Johnson, B. D., and Stankovich, M. T. (1992) Thermodynamic studies of medium-chain acyl-CoA dehydrogenase complexed to thioether-CoA ligands, Prog. Clin. Biol. Res. 375, 63-68.

45. Qin, L., and Srivastava, D. K. (1998) Energetics of two-step binding of a chromophoric reaction product, trans-3-indoleacryloyl-CoA, to medium-chain acyl-coenzyme-A dehydrogenase, Biochemistry 37, 3499-3508.

46. Peterson, K. M., Gopalan, K. V., and Srivastava, D. K. (2000) Influence of $\alpha-\mathrm{CH} \rightarrow \mathrm{NH}$ substitution in $\mathrm{C} 8-\mathrm{CoA}$ on the kinetics of association and dissociation of ligands with medium chain acylCoA dehydrogenase, Biochemistry 39, 12659-12670.

47. Reinsch, J. W., Feinberg, B. A., and McFarland, J. T. (1980) Intermediates during the fatty acyl CoA dehydrogenase catalyzed reduction of ETF by acyl CoA esters, Biochem. Biophys. Res. Commun. 94, 1409-1416.

48. Maniscalco, S. J., Tally, J. F., and Fisher, H. F. (2004) The interpretation of multiple-step transient-state kinetic isotope effects, Arch. Biochem. Biophys. 425, 165-172.

49. Fisher, H. F. (2005) Transient-state kinetic approach to mechanisms of enzymatic catalysis, Acc. Chem. Res. 38, 157-166. 
50. Palfey, B. A., and Fagan, R. L. (2006) An Analysis of the Kinetic Isotope Effects on Initial Rates in Transient Kinetics, Biochemistry $45,13631-13640$.

51. Kim, J.-J. P., Wang, M., and Paschke, R. (1993) Crystal structures of medium chain acyl-CoA dehydrogenase from pig liver mitochondria with and without substrate, Proc. Natl. Acad. Sci. U.S.A. $90,7523-7527$.

52. Venkatasubban, K. S., and Schowen, R. L. (1984) The proton inventory technique, Crit. Rev. Biochem. 17, 1-44.

53. Schowen, R. L. (2006) Hydrogen bonds, transition-state stabilization, and enzyme catalysis, in Isotope Effects in Chemistry and Biology (Kohen, A., and Limbach, H.-H., Eds.) pp 765-789, Marcel Dekker, New York.

54. Schowen, K. B., and Schowen, R. L. (1982) Solvent isotope effects of enzyme systems, Methods Enzymol. 87, 551-606.

55. Bowers, P., and Klevit, R. (2000) Hydrogen Bond Geometry and ${ }^{2} \mathrm{H} /{ }^{1} \mathrm{H}$ Fractionation in Proteins, J. Am. Chem. Soc. 122, 10301033.

56. Veglia, G., Zeri, A. C., Ma, C., and Opella, S. J. (2002) Deuterium/ hydrogen exchange factors measured by solution nuclear magnetic resonance spectroscopy as indicators of the structure and topology of membrane proteins, Biophys. J. 82, 2176-2183.

57. LiWang, A. C., and Bax, A. (1996) Equilibrium Protium/ Deuterium Fractionation of Backbone Amides in $\mathrm{U}_{-}{ }^{13} \mathrm{C} /{ }^{15} \mathrm{~N}$ Labeled Human Ubiquitin by Triple Resonance NMR, J. Am. Chem. Soc. 118, 12864-12865.

58. Kim, J. J., Wang, M., and Paschke, R. (1993) Crystal structures of medium-chain acyl-CoA dehydrogenase from pig liver mitochondria with and without substrate, Proc. Natl. Acad. Sci. U.S.A. 90, 7523-7527.

59. Wenz, A., Ghisla, S., and Thorpe, C. (1985) Studies with general acyl-CoA dehydrogenase from pig kidney. Inactivation by a novel type of "suicide" inhibitor, 3,4-pentadienoyl-CoA, Eur. J. Biochem. 147, 553-560.

60. Michaelis, L., and Menten, M. L. (1913) Die Kinetik der Invertinwirkung, Biochem. Z. 49, 333-369. 